\title{
(Un)skilled Leveraged Trading of Retail Investors*
}

\author{
Stephan Meyer ${ }^{\dagger}$ \\ Karlsruhe Institute of Technology University of Hohenheim \\ Sebastian Schroff $\ddagger$ \\ Christof Weinhardt ${ }^{\S}$ \\ Karlsruhe Institute of Technology \\ This version: February 7, 2013
}

\begin{abstract}
We study the trading behavior of retail investors in the market of leveraged bank-issued retail derivatives designed to trade excessively, speculate and gamble on ongoing trends and market movements. We analyze whether retail investors have private information and benefit disproportionately or whether they gamble. We answer this question along three dimensions: (i) profitability, (ii) news trading, and (iii) sensitivity to implicit trading costs. We distinguish derivatives by the type of underlying (index vs. individual stocks). We find that raw returns are negative for derivatives with stock as underlying, and only partially positive for those with index as underlying. Nevertheless, riskadjusted returns show a poor performance with sharpe ratios below one. We show that retail investors are attracted by news, but do not have private information prior to news events. Finally, we categorize investors according to their sensitivity to implicit trading costs. We find that non-sensitive investors perform worse than sensitive investors.
\end{abstract}

JEL Classification: G10, G14.

Keywords: Retail Investors, Gambling, Speculation, Implicit Trading Costs, Option Pricing, Bank-issued Derivatives

*Financial support from Boerse Stuttgart is gratefully acknowledged. The Stuttgart Stock Exchange (Boerse Stuttgart) kindly provided us with databases. The views expressed here are those of the authors and do not necessarily represent the views of the Boerse Stuttgart. An older version of the paper was circulated as 'Lottery Losses of Retail Investors'.

${ }^{\dagger}$ E-mail: stephan.meyer@kit.edu (corresponding author); Karlsruhe Institute of Technology, Research Group Financial Market Innovation, Englerstrasse 14, 76131 Karlsruhe, Germany.

${ }^{\ddagger}$ E-mail: sebastian.schroff@uni-hohenheim.de; University of Hohenheim, Chair of Banking and Finance, Germany.

${ }^{\S}$ E-mail: weinhardt@kit.edu; Karlsruhe Institute of Technology, Institute of Information Systems and Marketing, Germany. 


\section{Introduction}

From a traditional perspective, retail investor trading focused on stocks, bonds and funds motivated to build up one part of their overall retirement savings plan. Retail investors only rarely engaged in short-term speculation but rather followed conservative long-term investment strategies. Most securities had comprehensible risk-return combinations and retail investors did not have access to sophisticated trading strategies and opportunities to speculate on falling prices. This changed dramatically with the introduction of bank-issued product:11 specifically designed to grant retail investors access to sophisticated trading strategies and risk-return profiles for a broad range of different market expectations. This financial market innovation has reduced the gap between institutional and retail investors significantly. However, it remains unanswered if this innovation is beneficial regarding the wealth of retail investors.

Today's attitude of retail investors towards financial markets is no longer just a question of investing, but also includes speculation, and gambling as motivational factors. Many investors may think they have valuable information and can successfully speculate on future market movements, but more often it may just be an excuse to purse the gambling excitement and the thrill of adrenaline. Several studies have shown that retail investors lose on average due to excessive trading (Odean (1999), Barber, Lee, Liu, and Odean (2009), Barber and Odean (2000)). Barber and Odean (2000) state it pragmatically: 'Active investment strategies will under perform passive investment strategies. $2^{2}$

In Germany, the market for exchange-traded bank-issued products provides an ideal environment for retail investors to trade excessively, speculate and gamble on ongoing trends and market movements. Retail investors have easy access to leveraged bank-issued derivatives on stocks or indices which greatly magnify price fluctuations of the respective underlying. So far, there are no empirical investigations whether investors use leverage

\footnotetext{
${ }^{1}$ In this paper we use derivative and product as synonyms for those financial instruments specifically designed for retail investors.

${ }^{2}$ p. 800 , Barber and Odean (2000).
} 
products to incorporate private information and gain leveraged benefits, or whether it is primarily used as a casino-like 'financial playground' that facilitates retail investor gambling. In this paper, we address this question by analyzing how (un)informed retail investor trading in leverage products is.

A growing body of literature provides evidence that gambling is an important driver of retail investor trading activity: investors motivated by entertainment (Dorn and Sengmueller (2009)) or sensation seeking (Grinblatt and Keloharju (2009)) trade way more frequently than others ${ }^{3}$ Further, retail investors are attracted to assets with characteristics of a lottery, such as a high skewness of returns (Han and Kumar (2012), Brunnermeier and Parker (2007), Garrett and Sobel (1999), and Gaoa and Linb (2012)). Put differently, retail investors pay little attention to the expected return of an asset and give too much weight on the potential to generate extreme positive returns. Kumar (2009) finds that trades in lottery-like assets have a negative impact on investors' portfolio performance and Page, Spalt, and Kumar (2012) even observe a herding effect of such trades. As for the derivatives market Doran, Jiang, and Peterson (2011) find that retail investors are more attracted by lottery-like assets, such as out-of-the-money options, around New Year. Retail investor sentiment measures, trading volume and Las Vegas gambling volume supports their hypothesis. Lakonishok, Lee, Pearson, and Poteshman (2007) find that a huge number of non-market maker option trades can be attributed to speculation on the underlying asset prices, whereas Bauer, Cosemans, and Eichholtz (2009) find evidence for gambling in the option market and conclude that retail investors lose due to excessive trading and bad market timing. Hedging as an important explanation for retail investors to trade leveraged derivatives is rejected by Bauer, Cosemans, and Eichholtz (2009) and Schmitz and Weber (2012). Anderson (2008) empirically finds that investors who are likely to gamble are those with less capital at hand. Dorn, Dorn, and Sengmueller (2012) document a substitution effect between state lotteries and retail trading, and find that

\footnotetext{
${ }^{3}$ Dorn and Sengmueller (2009) show that retail investors trading for entertainment trade 'twice as much as those who fail to take pleasure in gambling or investing[...]', p. 602 .
} 
this effect is more pronounced for less educated male retail traders. Bauer, Cosemans, and Eichholtz (2009) add to this with the result that 'single men with low income and little investment experience are most likely to engage in [...] option trading [...].' $]^{4}$

In sum, retail investors who gamble in financial markets can be assigned three characteristics: (i) they trade more frequently, (ii) they have a poor performance, and (iii) they favor higher risk and leverage. We contribute to the literature by answering the following questions: do retail investors speculate successfully on short time horizons? Are retail investors informed or do they just gamble? We analyze whether retail investor trading is informed in three dimensions: (i) profitability, (ii) news trading, and (iii) implicit costs. We analyze profitability of trades with respect to volume, leverage and order type.

The group of leverage products consists of two distinct product types: Warrants and leverage certificates. Warrants are defined as bank-issued plain vanilla options. The key difference of leverage certificates, in comparison to warrants, is the additional feature of a so called 'knock-out barrier': if the price of the underlying hits or moves beyond a fixed designated threshold, the product becomes worthless immediately.

Our analysis focuses on leverage certificates instead of warrants, since leverage certificates are a non-suitable hedging instrument. We distinguish all results by the type of underlying (index vs. individual stocks). We find that raw returns are negative for certificates with stocks as underlying, and only partially positive for those with index as underlying. However, sharpe ratios are smaller than one on average which indicates a poor risk-adjusted performance. We find that trading activity of retail investors increases substantially around news. However, the performance of trading around news announcements is equally poor than trading performance at any other point in time. Finally, we categorize investors according to their sensitivity to implicit trading costs. We find that non-sensitive investors perform an order of magnitude worse than sensitive investors.

The remainder of this paper is structured as follows: Section 2 describes the retail investor market of bank-issued products. Our data is described in Section 3 including

\footnotetext{
${ }^{4}$ Quotation extracted from p. 745.
} 
descriptive statistics. Section 4 shows empirical results of overall retail investor performance, whereas Section 5 analyzes influencing factors such as volume, leverage ratio and order type. We analyze whether news trading is informed in Section 6, and whether retail investors are aware of implicit costs in Section 7. Section 8 concludes.

\section{The German Market of Bank-Issued Products}

Participating in options and futures markets is unfeasible for retail investors due to high commission and transaction costs. The market for bank-issued products therefore provides an useful extension to traditional spot markets in the sense that it grants retail investors access to sophisticated trading strategies. In Germany, having the most-advanced market for exchange-traded bank-issued products (securitized derivatives, structured products), investors can choose from more than one million different products with various payoff structures, underlyings, maturities and strike prices $5^{5}$ This extensive universe of products ensures that each investor can implement trading strategies that correspond to their individual market expectation and desired risk-return combination.

A fundamental aspect of this market structure is that liquidity for such products is (almost) solely provided by the issuing investment bank ${ }^{6}$ Therefore, the issuer dominates the price of a product and is able to include a premium to ensure guaranteed profits for himself. Several studies have analyzed magnitude and reaction of issuers' premiums to parameters such as moneyness and time to maturity (Stoimenov and Wilkens (2005), Baule, Entrop, and Wilkens (2008)). Issuers reduce premiums over the life time of a bank-issued product, which is known as the life cycle effect. Additionally, they anticipate demand of retail investors through the adjustment of the premium depending on the likelihood of higher upcoming buy or sell volume (Baule (2011)).

\footnotetext{
${ }^{5}$ See http://www.derivateverband.de/ENG/Statistics/MarketVolume for a up-to-date market statistic.

${ }^{6}$ Prices are set by the issuing investment bank. This way every trade usually has the issuing bank on the opposite side. Nevertheless, it is possible that at the same time a buy and sell trade of the same product is sent to the exchange and can be matched. This happens in less than $0.1 \%$ of all trades.
} 
Generally, the market for bank-issued products can be divided into long-term investment products with rather conservative payoff characteristics and short-term leverage products with more aggressive payoff structures. In our analysis, we focus on leverage products, which account for roughly $39 \%$ of total trading volume in bank-issued products.7 More precisely, we focus on leverage certificates as one out of two types of leverage products, excluding bank-issued plain vanilla options (warrants).

Generally, leverage certificates are useful in two dimensions: (i) they are ideally suited for speculative bets that can yield large gains (or, of course, large losses) within a very short time-horizon; (ii) informed investors can benefit much more strongly by entering highly leveraged positions and thus have strong incentives to trade corresponding products. The payoff $P_{C}\left(P_{P}\right)$ of a call (put) leverage certificate at maturity date $T^{*}$ is given through

$P_{C}=\left\{\begin{array}{l}S_{T^{*}}-X, \text { if } \forall 0 \leq t \leq T^{*}: S_{t}>X \quad P_{P}=\left\{\begin{array}{l}X-S_{T^{*}}, \text { if } \forall 0 \leq t \leq T^{*}: S_{t}>X \\ 0, \text { else }\end{array} \quad \text {, else }\right.\end{array}\right.$

where $S_{t}$ denotes the price of the underlying at time $t$ and $X$ the strike price of the leverage certificate, which is usually identical to the barrier. In other words the payoff price of a leverage certificate is simply the difference between current underlying price and barrier. The closer the barrier, the higher the leverage, risk, and potential profit. If the barrier has been touched, the product is 'knocked out' and the payoff is zero 8

\section{Data and Descriptive Statistics}

We focus on leverage certificates, designed for short-term speculation. Our sample period covers 238 trading days, ranging from April 1, 2009 until February 28, 2010. We obtain

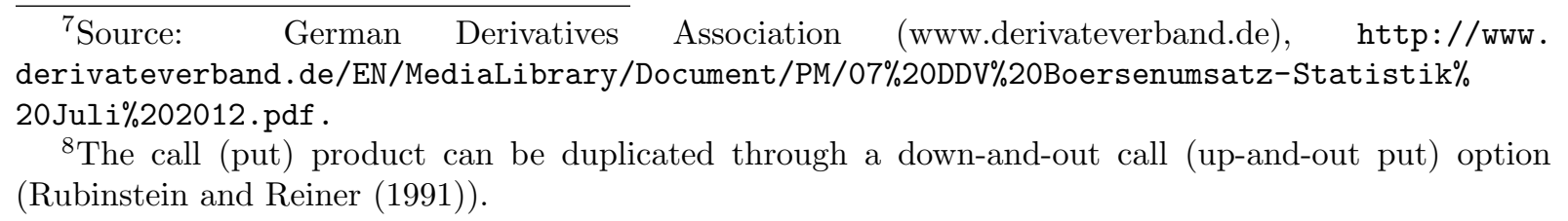


retail investor trade data and master data from Stuttgart Stock Exchange for all tradable leverage certificates. Stuttgart Stock Exchange is Germany's leading stock exchange for retail investors and Europe's leading specialist stock exchange for bank-issued products. It exclusively attracts order flow from retail investors and thus provides a unique environment to study the behavior of this group of investors. Algorithmic and high-frequency traders are banned from this exchange. Trade data observations contain an order number, timestamp, product identifier, trade price, and trade size. Timestamps are provided up to milliseconds. Additionally, we are able to identify the time between submission and execution of a trade. Master data contains information about product name, issuing investment bank, underlying, option type, first and last trading day, expiration date, knock-out barrier, strike level, and subscription ratio. We exclude endless leverage certificates with rolling barriers due to missing information about the barrier changes.

We build product quintiles according to the aggregated total trading volume for each leverage certificate. As sample, we focus on the most traded $20 \%$ of all leverage certificates with the German stock market index DAX as underlying. Additionally, we include all traded leverage certificates with a stock as underlying that has been a DAX constituent during the sample period..$^{9}$ We retrieve quote data on a one minute basis for each product throughout the sample period from Thomson Reuters DataScope Tick History archive through the Securities Industry Research Centre of Asia Pacific (SIRCA) 10 Quote data contains best bid, best ask as well as highest (lowest) bid and highest (lowest) ask during each one minute interval. We exclude leverage certificates for which no quote data can be obtained through SIRCA. Additionally, we exclude all certificates where strike price and knock-out barrier are not identical. In other words, we exclude all certificates with an integrated stop-loss barrier ${ }^{11}$ We obtain EUREX option data (option chain $\AA^{12}$ for all strikes and maturities for all underlyings in our sample. Option data is used to calibrate

\footnotetext{
${ }^{9} \mathrm{~A}$ list of all DAX constituents is shown in table 3 .

${ }^{10}$ We thank SIRCA for providing access to its data archive.

${ }^{11}$ This results in two products with DAX as underlying, and 252 with a DAX constituent as underlying.

${ }^{12}$ An option chain denotes a collection of put and call options on the relevant underlying beyond a wide range of strike prices but with same maturity (cf. EUREX website for details).
} 
our pricing model to derive implicit costs.

Archived news data is provided by Thomson Reuters NewsScope Content and is tagged through the Thomson Reuters NewsScope Sentiment Engine (RNSE) ${ }^{13}$ News are tagged with sentiment, relevance and novelty. Sentiment measures the degree of the textual content for each news item on a referred stock. It is either positive, negative or neutral. Relevance denotes a number between zero and one, and indicates the relevance of a news message for the referred stock. Novelty provides an indication whether there has been a news message with a similar content before. If more than one stock is mentioned in a news message, separate news entries are generated for each referred stock, with individual sentiment and relevance entries but the identical text message. Each news message is tagged with a primary news access code (PNAC) which allows for the identification of a developing story across multiple news messages. We keep the first entry of every news message group with the same PNAC and delete the rest to ensure a certain novelty of the news messages.

\subsection{Descriptive Statistics}

For all upcoming tables, we differentiate between leverage certificates with stock (DAX30 constituent) or index (DAX) as underlying. Panel A always reports results for the first group, whereas panel B shows results for the latter group. For simplicity reasons, we refer to a leverage certificate with index (stock) as underlying as index product (stock product). We distinguish between three overall data sets: (i) retail investor trade data, (ii) issuer quote data of leverage certificates, and (iii) Thomson Reuters news data. Table 11 shows descriptive statistics on our trade data set.

\section{INSERT TABLE 1 ABOUT HERE.}

\footnotetext{
${ }^{13}$ We thank Thomson Reuters for providing access to this data. For more details about the news data set refer to Storkenmaier (2011).
} 
In total, we combine 291, $740(38,149)$ trades in index (stock) products, 140, $823(19,631)$ buy orders and 150,917 $(18,518)$ sell orders, with a total trading volume of 2,270 (151) Mil. EUR. The average trade size is $7,781(3,970)$ EUR, whereas the median trade size is $1,812(1,436)$ EUR. We observe that volume in call stock products is almost three times the volume of put stock products. In contrast, volume in put index products is roughly $50 \%$ higher than volume in call index products. This opposing effect between the different underlying types has also been shown by Bauer, Cosemans, and Eichholtz (2009) for classic options. The higher volume in call stock products compared to put stock products is in line with results reported by Lakonishok, Lee, Pearson, and Poteshman (2007).

Table 2 reports descriptive statistics on our quote data set. Our sample includes 1, 583 different index products and 4, 487 stock products from 7 investment banks.

\section{INSERT TABLE 2 ABOUT HERE.}

Differentiated by option type, we obtain $791(3,039)$ call and $792(1,448)$ put index (stock) products. Banks are anonymized by relabeling them with characters A to G. Maturity at issuance ranges from 0.15 to 0.62 years for index products and from 0.26 to 0.70 years for stock products. Generally, index products have a shorter total lifetime than stock products. We define the moneyness of a product as $S_{t} / K$ for call products and $K / S_{t}$ for put products, where $K$ denotes the strike price and $S_{t}$ the underlying price at time $t$. The sample is homogeneous across issuing investment banks with respect to moneyness at issuance, ranging from 1.05 to 1.11 for index products, and 1,11 to 1.26 for stock products. In total, stock products are issued with a higher moneyness and a longer time to maturity compared to index products.

Table 3 provides an overview of our third data set: news messages. We incorporate a total of 12,556 news for 31 companies, which consists of 4,697 positive news, 2, 195 neutral news, and 5,664 negative news. On average, we observe 405 news per company. 


\section{INSERT TABLE 3 ABOUT HERE.}

\section{Profitability}

Our unique data set allows us to study the behavior of the general population of retail investors who trade leverage certificates since it is not restricted to a certain broker type or bank. If aggregated retail investors trading in leverage certificates is informed, their trading activity should be profitable on average. In contrast, if investors are uninformed and use leverage certificates to gamble, we can expect them to be on the right side of the market in $50 \%$ of all trades on average. Obviously, retail investors' profession is not trading, but they may work for companies that have business relationships with one or more underlying stocks in our sample. This might be a source of private information or a more experienced understanding of a company. Investors with private information would therefore rather buy stock products than index products to isolate all other information which might drive the market.

On the other hand, investors with interest in gambling would rather pick index products, since a broader range of barrier levels as well as higher leverage ratios are available.14 The leverage ratio of a product $i$ measures the sensitivity of the product's price relative to the price of the underlying. The leverage ratio of a product $i$ at time $t$ can be computed as follows:

$$
\text { Leverage }_{i t}=\frac{S_{i t}}{L P_{i t}} \times c_{i}
$$

where $L P_{i t}$ denotes the price of product $i$ at time $t, S_{i t}$ denotes the price of the underlying,

\footnotetext{
${ }^{14}$ In October 2012, 60,4\% of all tradable leverage certificates had an index as underlying, $19,6 \%$ a stock, and 15,2\% a commodity. Source: German Derivative Association, October Statistic, 2012, http://www.derivateverband.de
} 
and $c_{i}$ denotes the subscription ratio 15 The leverage ratio of a product is changing constantly, depending on the movement of the underlying. For leverage certificates, a higher leverage ratio is associated with a higher risk of a total loss, since it is more likely that the knock-out barrier is hit.

We compute the performance of each buy order in our sample for different holding periods. Let $s_{i j}$ be the size of trade $j$ in product $i, b_{i t}$ the (best) bid price of product $i$ at time $t$, and $f$ constant transaction costs for a single trade, i.e. half a round trip. Let $L P_{i t_{0}(j)}$ be the price at which trade $j$ at time $t_{0}(j)$ is executed. All other variables are as defined before. Let $\operatorname{Ret}_{i j h}$ be the percentage raw return of trade $j$ in product $i$ for the holding period $h$ :

$$
\operatorname{Ret}_{i j h}=\left\{\begin{array}{l}
\frac{\left(b_{i t_{0}+h} \times s_{i j}-f\right)-\left(L P_{i t_{0}(j)} \times s_{i j}+f\right)}{L P_{i t_{0}(j)} \times s_{i j}+f} \times 100, \\
\quad \text { if } b_{i t_{0}+h} \times s_{i j}>f \wedge \forall t_{0}(j) \leq t \leq t_{0}(j)+h: S_{t}>X \\
-100, \text { else. }
\end{array}\right.
$$

The condition $b_{i t_{0}+h} \times s_{i j}>f$ represents the case that an investor would not close his position if transaction costs are higher than the value of his position. In case of a knock-out, the position is automatically eliminated by the broker of the investor without additional costs. Investors' performance in leverage certificates is difficult to compare across each other, since leverage ratios and associated risks are different for each trade. Hence, we calculate the risk-adjusted return $\operatorname{Ret}_{i j h}^{A d j}$ (sharpe ratio) as

$$
\operatorname{Ret}_{i j h}^{A d j}=\frac{\operatorname{Ret}_{i j h}}{\sigma_{i}\left[t_{0}(j), t_{0}(j)+h\right] \times \text { Leverage }_{i t_{0}(j)}}
$$

where $\sigma_{i}\left[t_{0}, t_{0}+h\right]$ denotes the standard deviation of the product's underlying between the time of purchase $t_{0}$ and the end of the holding period $t_{0}+h$. We multiply the standard deviation of the underlying with the current leverage ratio of the product since product

\footnotetext{
${ }^{15}$ The purpose of the subscription ratio is to scale down the price of a leverage certificate to an investorfriendly level. The subscription ratio in our sample varies between 0.01 and 1 .
} 
prices react accordingly to the leverage ratio larger than the corresponding underlying. A leverage ratio of 9 , for example, indicates that the price of the leverage product moves by $9 \%$ given a price movement of $1 \%$ of the underlying. We assume constant conservative transaction costs of 5 EUR $(f=5.00)$ per trade ${ }^{16}$ Using risk-adjusted returns allows for a better comparability due to the normalization of raw returns to the risk taken. Unfortunately, negative returns can therefore not be interpreted meaningfully, because absolute losses are reduced by higher risk.

Table 4 reports average raw and risk-adjusted returns across all trades distinguished by the type of underlying. Entrop, Schober, and Wilkens (2011) find that the average holding period for leverage certificates is 1.17 days. For robustness, we calculate returns for holding periods of $30 \mathrm{~min}, 1 \mathrm{~h}, 2 \mathrm{~h}, 3 \mathrm{~h}, 4 \mathrm{~h}, 1 \mathrm{~d}, 2 \mathrm{~d}$, and 5 days. Holding periods refer to actual trading hours. Periods exceeding trading hours of a day are continued in trading hours on the following day. For example, the performance for the $1 \mathrm{~h}$ holding period of a trade executed 10 min before the end of the trading period of a day is calculated using the quote 50 min after the opening on the next trading day. We use this tradinghour approach rather than calculating performance for the exact difference in time, since otherwise holding periods less than a day do not change for trades executed towards the end of the day.

\section{INSERT TABLE 4 ABOUT HERE.}

We find the performance of retail investors to differ between underlyings. In total, retail investor trades in leverage products with stocks as underlying generate negative raw returns that vary between $-4.96 \%$ and $-9.45 \%$ for the different holding periods. In contrast, trades in index products generate positive raw returns for holding periods greater than four hours. In total raw returns are ranging between $-1.79 \%$ and $7.82 \%$ for all holding periods.

\footnotetext{
${ }^{16}$ As of January 2013 , the cheapest German broker has round trip costs of at least 10 EUR.
} 
Our sample period is characterized by a bullish market development with a $30 \%$ increase of the German stock market index DAX. Accordingly, it can be argued that the positive returns in index products are driven by generally rising market prices and not by investors' skills. This argument could also be applied to investors' performance in stock products because all stocks in our sample are part of the same bullish index. Nevertheless, investors trading stock products perform worse compared to those investing in the index itself.

When looking at risk-adjusted returns, we observe negative returns for index products for assumed holding periods below 4 hours. Average sharpe ratios across all trades in index products for all holding periods are below 0.3 , which implies a poor risk-adjusted performance. Such low sharpe ratios reflect either unawareness of risk by retail investors, or a strong desire for high leverage ratios that dominates the associated risk.

Since we exclude warrants (bank-issued plain vanilla options) from our analysis, and focus on leverage certificates, we exclude portfolio hedging considerations as motivation behind trades. We therefore argue that a poor performance in leverage certificates has a negative influence on investor wealth.

\section{Leverage, Volume, and Order Types}

Which characteristics influence the profitability of retail investors' leveraged trades? To answer this question, we study returns with respect to trading volume, leverage ratio, and order type. Better informed investors might trade with higher volume or leverage ratio to increase their expected profit. Figure 1 visualizes the trade frequency with respect to the taken risk differentiated by underlying type (upper figure: stock products; lower figure: index products) and option type (gray bars: call; black bars: put).

INSERT FIGURE 1 AND 2 ABOUT HERE. 
The average traded leverage ratio is higher for index products than for stock products. We observe that most trades are executed at leverage ratios between 5 and 60 for index products and between 1 and 20 for stock products. Both distributions are skewed towards high leverage ratios and they do not differ between option types. In other words, retail investors are willing to face the same risk when entering long or short positions, but they face higher risks when trading index products compared to stock products.

Figure 2 illustrates the invested volume of retail investors. Most orders are smaller than 5, 000 EUR with a great part residing below the threshold of 1,000 EUR. Combining those results of small invested capital and high leverage ratios brings to mind the character of a lottery ticket: small costs but high potential profits. Table 5 shows average raw returns differentiated by leverage ratio terciles.

\section{INSERT TABLE 5 ABOUT HERE.}

We report mean and median raw returns to avoid a probably misleading interpretation of trades with high leverage ratio due to the skewed return distribution $[17$ For both stock and index products we observe a negative return for retail investors trading with medium or low leverage ratios for all considered holding periods. For trades with high leverage ratios in stock products we observe the highest relative losses. Results indicate that for trades in stock products it holds that the higher the leverage, the worse the return. As for index products there is a slight window between holding periods of 2 hours and 1 day when trades with high leverage ratio are profitable on average. For longer holding periods we observe a negative median performance and for the 5 day holding period we obtain a median return of almost $-100 \%$, which represents a total loss of all invested capital across all trades.

\footnotetext{
${ }^{17}$ Highly leveraged trades are likely to suffer a total loss, which results in a skewed distribution of raw returns towards $-100 \%$.
} 
In short, retail investors perform poorly trading stock products, independently from the leverage ratio, but intraday trades on the index are profitable on average.

In the following we analyze the profitability of trades in more detail with respect to other order characteristics. Kelley and Tetlock (2012) analyze retail investor performance with respect to the order type and find that only market orders predict upcoming news events. We define an order as marketable if it is executed within one second after submission. All other orders are labeled limit orders. Let Volume $_{i j}$ denote the number of shares bought times buy price $\left(L P_{i t_{0}(j)} \times s_{i j}\right)$, and $L$ everage $e_{i t_{0}(j)}$ be the leverage ratio of buy order $j$. We standardize ${ }^{18}$ both variables prior to analysis to improve comparability of the influencing factors. Since we use relative returns and total losses are likely to occur, our dependent variable has a lower bound: $\operatorname{Ret}_{i j} \geq-100$. Consequently, we use a truncated regression mode 19 .

$$
\text { Ret }_{i j h}=\alpha+\beta_{1} \times \text { Leverage }_{i t_{0}(j)}+\beta_{2} \times \text { Volume }_{i j}+\beta_{3} \times D_{i j}^{\text {Limit }}+\beta_{4} \times D_{i j}^{\text {Call }}+\epsilon_{j},
$$

where $D_{i j}^{\text {Limit }}$ denotes a dummy variable set to one if the order is a limit order and zero otherwise; $D_{i j}^{C a l l}$ is a dummy variable indicating a call $(=1)$ or put $(=0)$ product. We run the regression separately for each assumed holding period. Table6 6 reports results for the above regression model for stock products (panel A) and for index products (panel $\mathrm{B})$.

\section{INSERT TABLE 6 ABOUT HERE.}

We observe that investors who trade products with higher leverage ratios are more successful than others for holding periods longer than two hours. The performance of large

\footnotetext{
${ }^{18}$ We standardize a variable in the following way: variable $=($ variable $-\overline{\text { variable }}) / \mathrm{STD}($ variable $)$.

${ }^{19}$ Our results are robust if we exclude individual variables from the model. Additionally, an interaction effect of volume and leverage is not significant. Using a standard regression model or a logit model instead of our truncated regression model does not change the effects. Transformation $\left(\left(\operatorname{Ret}_{i j h}\right)^{3}\right)$ of raw returns also has no effect on the direction of the estimated coefficients.
} 
trades varies between underlying types. Larger trades in stock products are on average more successful, whereas the opposite holds for index products. For holding periods up to four hours we observe for both underlying types that investors who use market orders generate higher returns than those who use limit orders. For trades in stock products, this relationship holds for all holding periods. Market orders indicate that investors are interested in a fast execution which might be an indicator of more informed trading compared to investors using limit orders (Harris (2001)) ${ }^{20}$ Investors trading call products have a better performance on average than those trading put products. We attribute this difference to the bullish market development during our sample period.

\section{News Trading}

Retail investors seem to perform badly when trading stock products. To provide more detailed insights we analyze retail investors entered positions in leverage certificates around news announcements. Figure 3 visualizes the number of executed buy orders in stock products and the corresponding number of news announcements across all underlyings in our sample.

\section{INSERT FIGURE 3 ABOUT HERE.}

It seems that investors trade more intensively around news announcements. Barber and Odean (2008) find that retail investors react to news on spot markets and pick attentiongrabbing stocks. We analyze retail investors trading intensity around news through the following regression model. We aggregate all executed buy orders on a minute basis and calculate the number of trades, trading volume, and entered long and short positions. We

\footnotetext{
${ }^{20}$ Traditional literature focuses on market vs. limit orders from a market microstructure perspective. Results retrieved are only of limited use in our market since there is a guaranteed execution at the current best bid and best ask price for volume up to 20,000 EUR. For stock markets Anand, Chakravarty, and Martell (2005) argue that informed investors, are using both limit and market orders.
} 
build intervals $I_{1}, I_{2}$, and $I_{3}$ for different periods before and after news, similar to Riordan, Storkenmaier, Wagener, and Zhang (2012):

$$
I_{n t}= \begin{cases}1 & n=1: \text { if } \mathrm{t} \text { is } 6 \text { hours before a news } \\ & n=2: \text { if } \mathrm{t} \text { is } 6 \text { hours after a news } \\ 0 & \text { else. }\end{cases}
$$

We use 6 hour periods to account for a possibly delayed reaction of retail investors to news which might occur due to regular job duties for example. We build sentiment dummy variables $S_{m t}$ separately for positive $(m=1)$, negative $(m=2)$, and neutral $(m=3)$ news announcements. They are set to one within a range of six hours around a positive, negative, and neutral news event, respectively. Let $l$ denote an observation in our data set, and $x$ denote the underlying. We include dummy variables for the underlying $(U)$, for the hour of the day $(T)$, and the day of the week $(W)$. Let $M_{x l}$ denote the trading intensity measure (\#Trades, Volume, \#Long, \#Short) for underlying $x$ and observation $l$. The regression is then modeled as follows:

$$
M_{x l}=\alpha+\sum_{n=1}^{2} \sum_{m=1}^{3} \psi_{n m} I_{n x l} S_{m x l}+\sum_{x=1}^{30} v_{x} U_{x}+\sum_{t=1}^{11} \tau_{t} T_{t}+\sum_{d=1}^{4} \omega_{d} W_{d}+\epsilon_{x}
$$

We use generalized method of moments for the estimation and correct standard errors for heteroscedasticity effects and serial correlation using the procedure proposed by Newey and West (1987). Consequently, we obtain results for the trading intensity six hours before and after news, relative to periods of no news, and with respect to the sentiment of news.

\section{INSERT TABLE 7 ABOUT HERE.}


Table 7 reports results for the above regression model, excluding all control variables for clarity reasons. As indicated by Figure 3, the number of trades in leverage certificates is higher around news events of the underlying. This is in line with research on ordinary stocks by Riordan, Storkenmaier, Wagener, and Zhang (2012), and Berry and Howe (1994). Overall, we observe positive results for all trading intensity measures around news, except for trading volume before neutral news. The increase in entered short positions compared to long positions is higher before positive and neutral news, and lower before negative news. After positive and neutral news entered long positions increase more than short positions, whereas after negative news we observe a balanced increase for both trade directions. In general, negative news attract the most order flow compared to positive and neutral news. Put differently, retail investors enter more short positions before positive news, and more long positions before negative news. This behavior provides strong evidence that retail investors trading leverage certificates do not posses an informational edge and have poor predictive capabilities.

To calculate the actual profitability around news events, we calculate for each trade the difference in time to the next news after the trade which refers to the specific underlying stock. We cluster trades by the passing time until the next news event occurs. We group trades that have been executed within 30 minutes before a news event in the underlying, between 30 minutes and one hour, one hour and 5 hours, 5 hours and 24 hours, and earlier than that. Table 8 reports results for the predictive capabilities of retail investor trades.

\section{INSERT TABLE 8 ABOUT HERE.}

We exclude all combinations of holding periods and time differences which would refer to a sell of the position before the time of arrival of the actual predicted news. Retail investors have a negative performance at all times, which implies that informational advantages can be ruled out as trading motivation. Raw returns range from $-4.71 \%$ to $-12.31 \%$. 
Summarizing, retail investors are attracted by news events, but have no informational advantage whatsoever. Due to the leverage of the analyzed products, they lose substantial amounts of money within a short period of time. Barber and Odean (2000) argue that this behavior of increased trading activity but poor performance can be explained through the overconfidence of retail investors.

\section{$7 \quad$ Implicit Trading Costs}

We already know that raw and adjusted performance of retail investors differs between underlying types. Retail investors trading leverage certificates with a stock as underlying perform poorly. Their news trading activity indicates that they wrongly think they can correctly trade on the news. Having provided evidence for retail investors being uninformed while trading stock products, we now analyze retail investors' trades in index products with respect to a different type of information: implicit trading costs.

Every single bank-issued product is issued by just one investment bank and therefore liquidity is only provided by this bank. Issuers continuously quote prices for their own products, which depend on their chosen valuation model and input parameters. Since most products are of a complex nature and retail investors usually do not posses the skills and knowledge necessary to calculate a theoretical fair price, issuers can easily incorporate premiums into prices. Depending on the relative lifetime of a product, moneyness, and investor demand, investment banks adjust the incorporated premium of their products (Baule, Entrop, and Wilkens (2008), Baule (2011)). As a result, banks gain risk-free profits in return.

We define the relative percentage premium $P_{i t}$ of a leverage certificate $i$ at time $t$ as the relative difference between the observed quoted price $L P_{i t}^{o b s}$ and the calculated theoretical price $L P_{i t}^{\text {the }}$ :

$$
P_{i t}=\frac{L P_{i t}^{o b s}-L P_{i t}^{t h e}}{L P_{i t}^{t h e}} \times 100
$$


We calculate theoretical prices using the Practitioners Black-Scholes model (PBS) (Black (1985)).21 We re-calibrate the implied volatility parameter of the model for every single product on every minute, using all available DAX option chains tradable at EUREX.

In this section, we analyze whether retail investors are sensitive towards implicit costs of leverage certificates. Implicit costs consist of the product premium and the spread. Since liquidity is always provided by the issuing investment bank, spreads are kept almost constant. Depending on the issuer, spreads are usually either one or two cent. The higher the leverage ratio, and therefore the closer the barrier, the smaller the price of the leverage certificate. As a result, higher leverage is associated with higher relative spreads. To measure the potentially higher profit through higher leverage ratios with respect to the increase of existing implicit costs, we introduce a net leverage measure which is defined as follows:

$$
\text { Leverage }_{i t}^{\text {Net }}=\frac{\text { Leverage }_{i t}}{P_{i t}+\text { Spread }_{i t}}
$$

where Spread $_{i t}=\frac{a_{i t}-b_{i t}}{a_{i t}} \times 100$ and $a_{i t}\left(b_{i t}\right)$ denotes the best ask (bid). Since we want to capture the net leverage at the moment of the buy decision we divide the absolute spread by the ask price instead of the mid price since investors have to buy the leverage certificate at the ask price. Figure 4 shows net leverage with respect to the moneyness of the product for call and put products, respectively.

\section{INSERT FIGURE 4 ABOUT HERE.}

We observe a strong decrease of the net leverage in both figures below a moneyness level of $1.4 \%$, meaning that implicit costs increase more than the associated leverage ratio. This is due to the enormous relative increase of the spread, since leverage certificates very close

\footnotetext{
${ }^{21}$ For more details regarding the underlying option structure see Appendix $\mathrm{A}$.
} 
to the barrier have usually very small prices, while the absolute spread remains constant for all product prices.

Trading at such low levels of moneyness requires investors to pay close attention to the underlying, since a total loss is likely to occur on the same day or even within the next hours. The required amount of time to monitor the positions makes it seem more like watching a game or, to be a little exaggerated, the drawing of a lottery. Investors trading leverage certificates with a smaller net leverage should therefore either be highly informed, or have a preference for high leverage ratios, independent of associated costs and risks. Bauer, Cosemans, and Eichholtz (2009) find that investors prefer out-of-the-money options due to the higher leverage and the lottery-like characteristics. Since leverage certificates are worthless out-of-the-money due to the knock-out barrier, leverage certificates at small moneyness levels can be seen equivalently to out-of-the-money plain vanilla options. They offer a high leverage ratio, i.e. small probability of a high return, for a very cheap price.

We define two types of investors depending on the traded net leverage. Investors buying products with leverage $e_{i t}^{\text {Net }}<2.5$ are defined non-sensitive investors. All others are defined sensitive investors. Generally, we expect sensitive investors to be more rational regarding their information level and therefore more profitable on average. On the other hand, investors who trade with high leverage ratios could experience a positive performance as well due to the motivation to strongly benefit from their private information. However, it seems more likely that non-sensitive investors are just trading to pursue their gambling excitement and have no information on average. Table 9 reports results of the profitability analysis of those two investor types.

\section{INSERT TABLE 9 AND 10 ABOUT HERE.}

Non-sensitive investors have a negative raw return for all considered holding periods, 
whereas sensitive investors experience a strong positive return. On average, non-sensitive investors lose between $3.36 \%$ and $18.92 \%$ compared to sensitive investors. Returns tend to decrease with longer holding periods for non-sensitive investors and increase for sensitive investors. Table 10 provides similar results based on net leverage terciles. ${ }^{22}$

Hence, retail investors who value leverage more than implicit costs suffer significant losses by trading leverage certificates. Ignoring higher implicit costs supports the hypothesis that retail investors are either ignorant or trade for entertainment. Nevertheless, risk-adjusted returns show that no matter at which point in time capital is invested in leverage certificates, on average it is always a poor investment with respect to the risk incurred.

\section{Conclusion}

Investing should be more like watching paint dry or watching grass grow. If you want excitement, take $\$ 800$ and go to Las Vegas.

Paul Samuelson, Nobel laureate Several studies have shown that retail investors trade excessively and tend to favor stocks with lottery-like characteristics. This paper investigates the trading behavior of retail investors in a market dedicated to short-term speculation and gambling. German investment banks provide retail investors with the opportunity to trade highly leveraged products ideally suited to speculate and/or gamble.

We find that retail investors' performance strongly depends on the underlying type of the investment: index or stock. They have a positive return if they speculate on intraday index movements, and a negative when speculating on single constituents. However, riskadjusted returns show that overall investment strategies involving leveraged derivatives perform badly on a risk-adjusted basis. Retail investors using market orders tend to have higher returns than those using limit orders to buy leverage products.

\footnotetext{
${ }^{22}$ Distinguishing terciles by option type does not have any substantial effect on the returns.
} 
Trading intensity of retail investors in products with a stock as underlying increases around news. Negative news attract more trades than positive or neutral ones. However, retail investors do not have any informational advantage and no predictive power whatsoever. They enter more short positions before positive news, and more long positions before negative news, which results in consistently negative returns.

We calculate the incorporated hidden premium of products for all index products using the Practitioners Black-Scholes model. We find that investors which are sensitive to implicit costs, i.e. spread and premium, perform considerably better than those that favor leverage at any price. Sensitive investors have on average a between $3.47 \%$ and $19.10 \%$ higher return than non-sensitive investors. Again, profitability with respect to the taken risk is badly, with sharpe ratios smaller than one.

Products with extreme returns for 'correct bets' seem to greatly attract speculators and gamblers. It seems that investors are more or less decreasing their wealth to indulge in the adrenaline of trading highly leveraged products. 

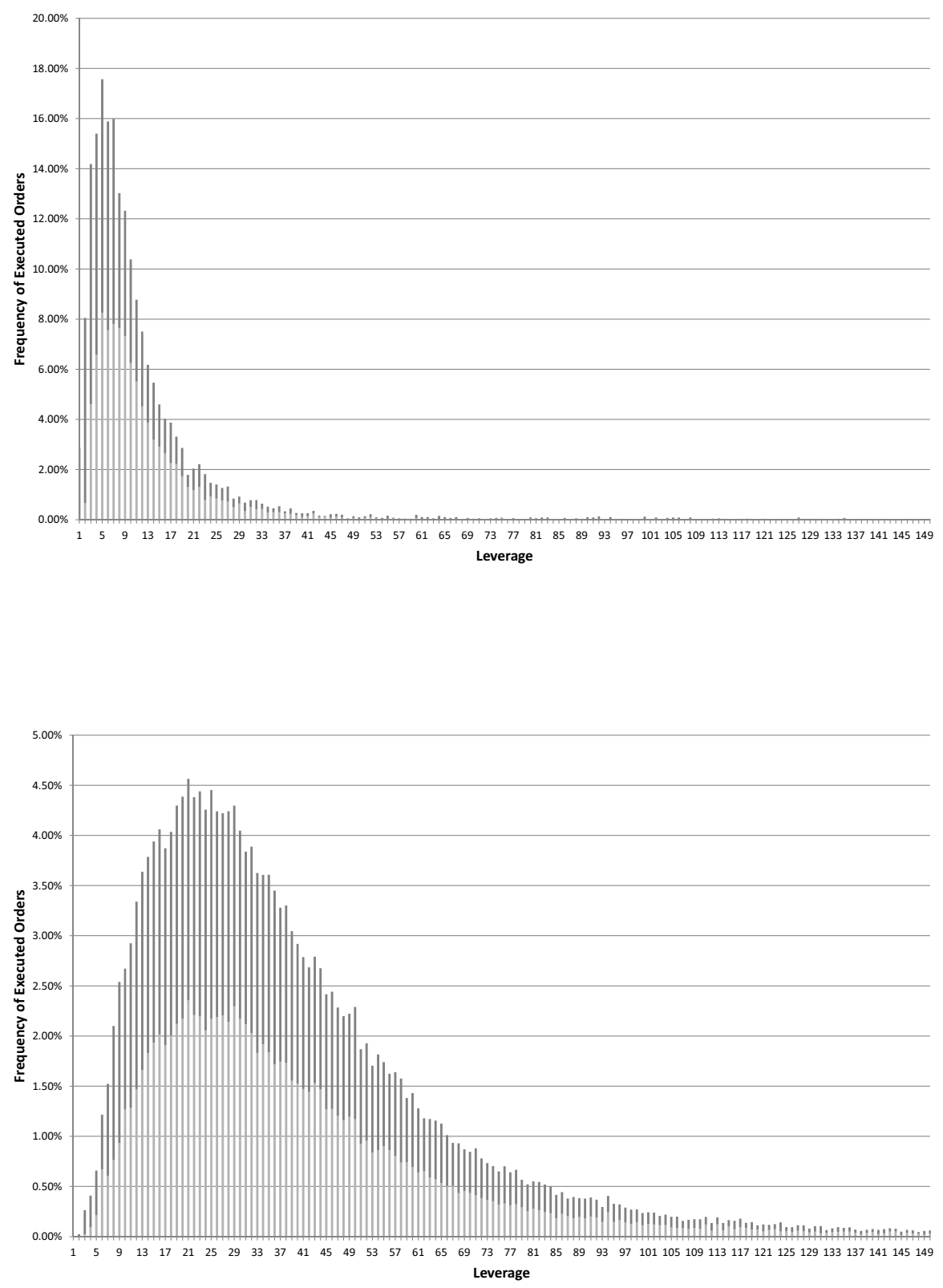

Figure 1

Risk-Habitat

Both figures visualize the frequency of executed buy orders in leverage certificates by retail investors with respect to the traded leverage ratio. $\mathrm{X}$-axis shows the leverage ratio and $\mathrm{y}$-axis shows the frequency. The gray bars denote the number of call positions and the black bars the number of put positions. The upper figure visualizes this relationship for leverage certificates with stocks as underlying, whereas the lower figure shows the case for index as underlying. 

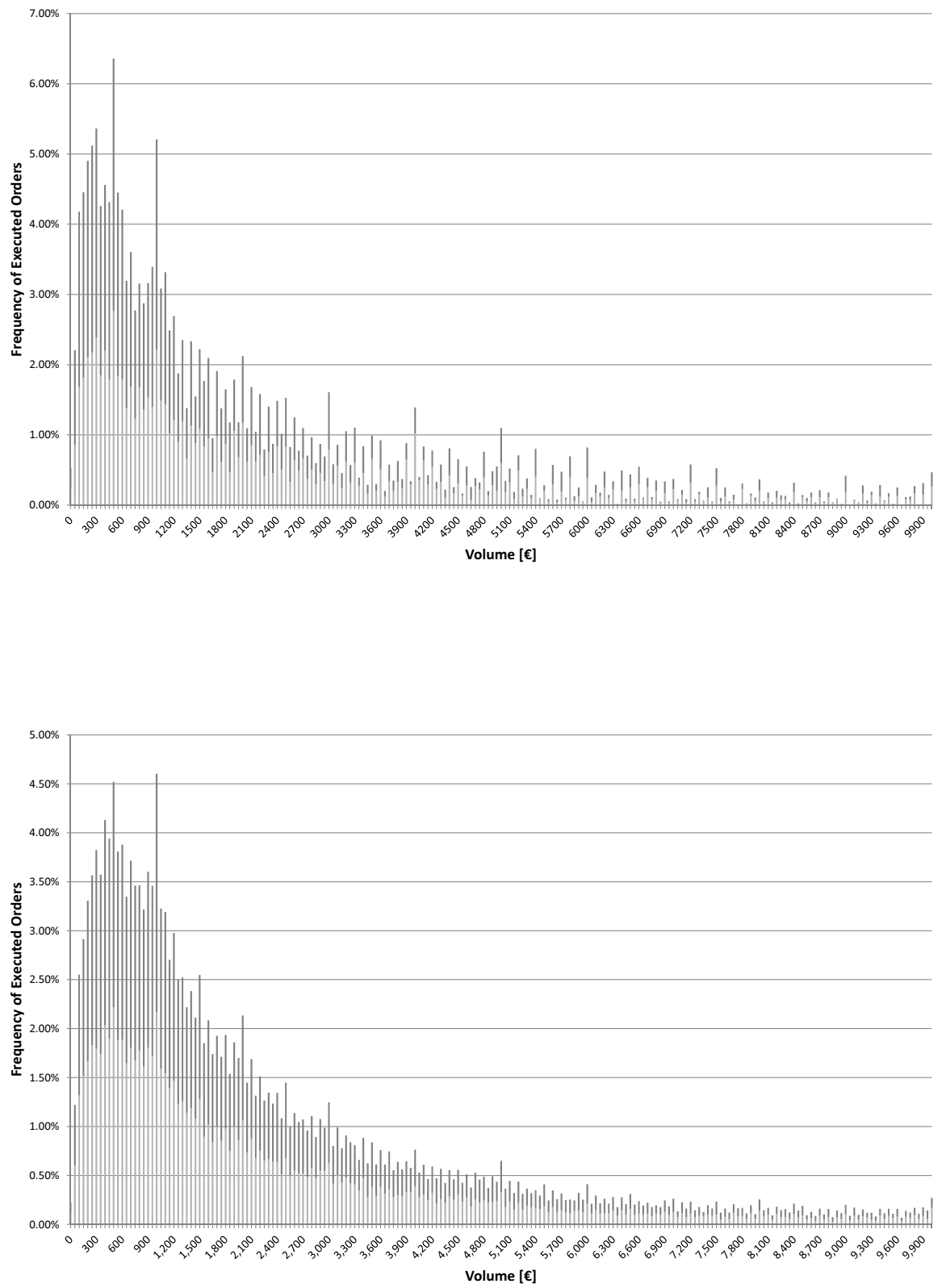

Figure 2

\section{Invested Capital}

Both figures visualize the frequency of executed buy orders in leverage certificates by retail investors with respect to the invested volume (price $\times$ size). $\mathrm{X}$-axis shows the leverage ratio and $\mathrm{y}$-axis shows the frequency. The gray bars denote the number of call positions and the black bars the number of put positions. The upper figure visualizes this relationship for leverage certificates with stocks as underlying, whereas the lower figure shows the case for index as underlying. 


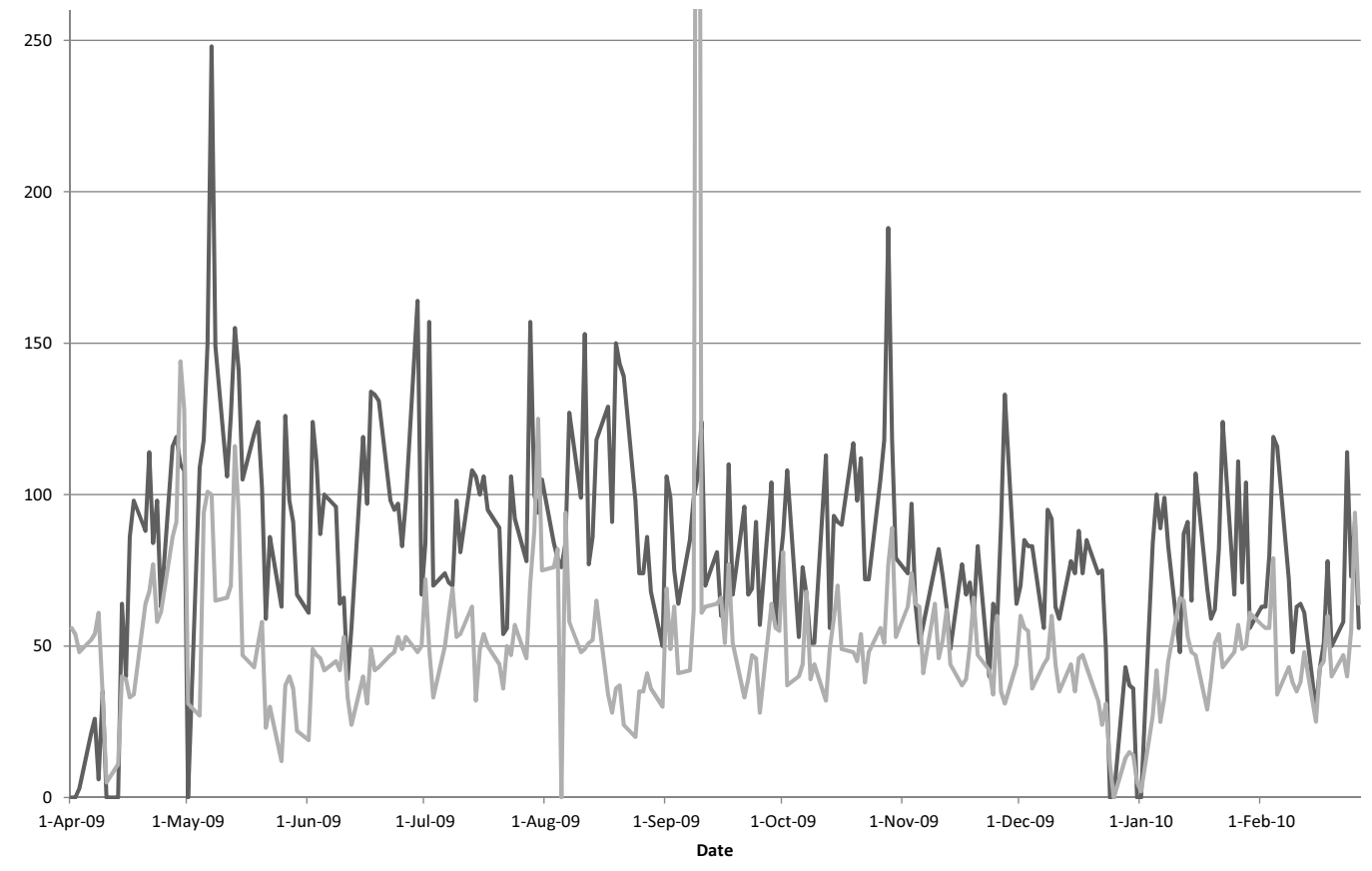

Figure 3

News and Trades

This figure visualizes the total number of news and trades in leverage certificates with a stock as underlying. X-axis shows the date, and $\mathrm{y}$-axis represents the number of news and trades occurring on the individual day. The black line denotes the number of trades, and the gray line the number of news. We reduced the vertical axis to 250 for reasons of clarity. 

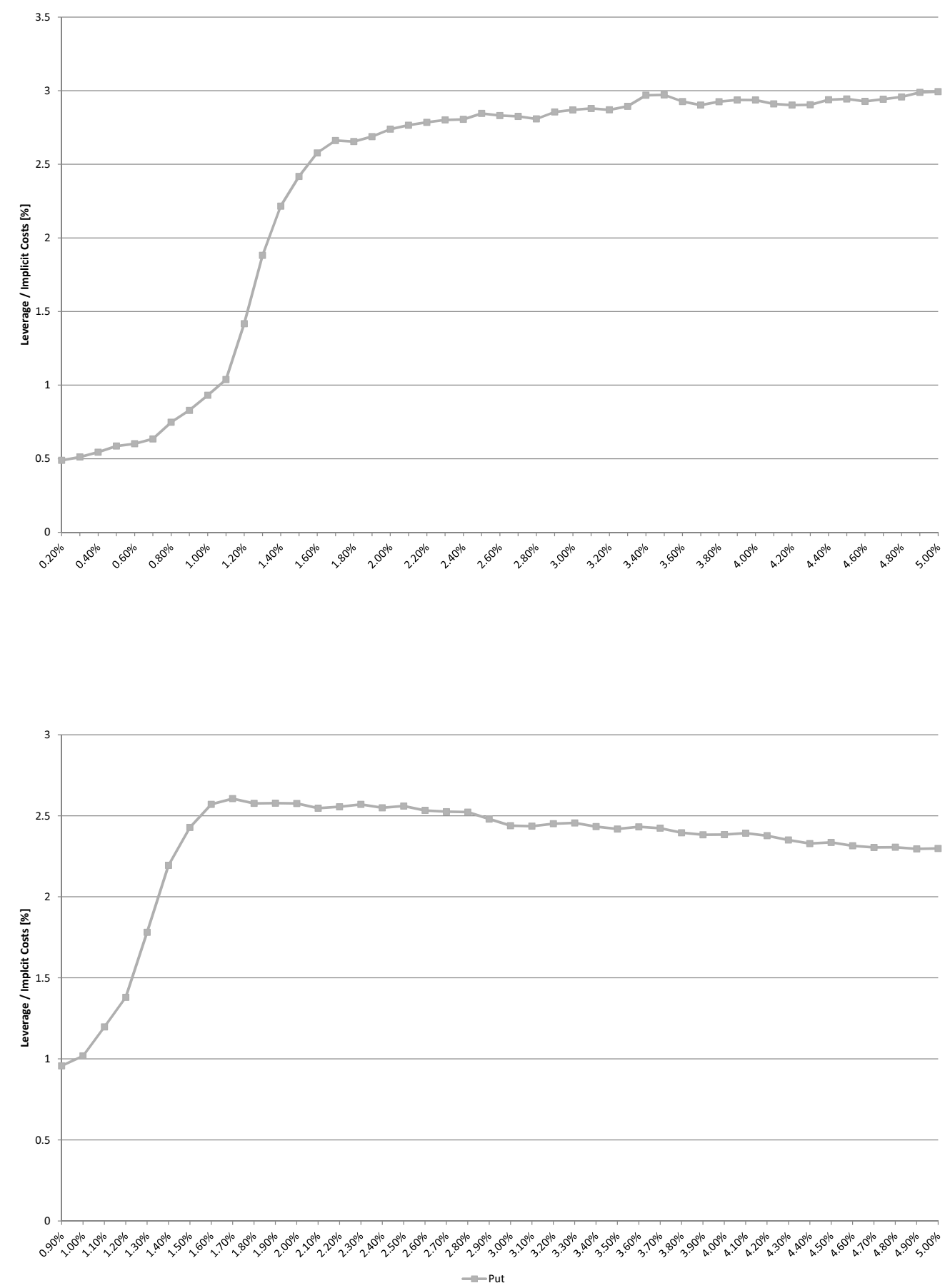

Figure 4

Leverage vs. Implicit Costs

These figures plot values for leverage divided by implicit costs with respect to moneyness ranging from $0 \%$ to $5 \%$. Implicit costs consist of the hidden product premium and the bid-ask spread. The upper figure refers only to call products, whereas the lower figure shows the ratio for put products. 
Table 1

Descriptive Statistics - Trades

This table reports descriptive statistics of our trade data sample. Our sample includes all customer trades of the Stuttgart Stock Exchange for all products shown in Table 2 Standard deviations are reported in brackets.

\begin{tabular}{lrr}
\hline & \multicolumn{2}{c}{ Underlying Type } \\
& \multicolumn{1}{c}{ Stock } & \multicolumn{1}{c}{ Index } \\
\hline Total Volume [kEUR] & 151,449 & $2,270,105$ \\
Buy Volume [kEUR] & 72,620 & $1,109,062$ \\
Sell Volume [kEUR] & 78,828 & $1,161,043$ \\
& & \\
Call Volume [kEUR] & 111,246 & 899,251 \\
Call Buy Volume [kEUR] & 54,051 & 431,896 \\
Call Sell Volume [kEUR] & 57,195 & 467,354 \\
& & \\
Put Volume [kEUR] & 40,203 & $1,370,854$ \\
Put Buy Volume [kEUR] & 18,570 & 677,166 \\
Put Sell Volume [kEUR] & 21,633 & 693,688 \\
& & \\
\# Trades & 38,149 & 291,740 \\
\# Buys & 19,631 & 140,823 \\
\# Sells & 18,518 & 150,917 \\
& & \\
Mean Trade Size [EUR] & 3,970 & 7,781 \\
Median Trade Size [EUR] & $(8,679)$ & $(50,950)$ \\
\hline & & 1,812 \\
\hline
\end{tabular}


Table 2

Descriptive Statistics - Quotes

This table reports descriptive statistics of our quote data sample, starting from April 1st, 2009 until February 28th, 2010. It includes 4, $487(1,583)$ leverage certificates with a stock (index) as underlying, issued by seven different investment banks. We report the number of call and put products, mean maturity $\left(T-t_{0}\right) / 365$ (where $t_{0}$ is the issuance date) in years, and moneyness: $S_{t_{0}} / K$ for call products and $K / S_{t_{0}}$ for short products (where $K$ is the strike price and $S_{t_{0}}$ the index level at issuance). Panel A and B report results differentiated by the underlying type. Standard deviations are reported in brackets.

\begin{tabular}{|c|c|c|c|c|c|}
\hline \multirow{2}{*}{$\begin{array}{l}\text { Panel A: stock as underlying } \\
\text { Investment Bank }\end{array}$} & \multirow[b]{2}{*}{ \#Products } & \multirow[b]{2}{*}{ \#Calls } & \multirow[b]{2}{*}{ \#Puts } & \multicolumn{2}{|c|}{ At Issuance } \\
\hline & & & & Maturity & Moneyness \\
\hline \multirow[t]{2}{*}{ B } & 1,261 & 927 & 334 & 0.32 & 1.16 \\
\hline & & & & $(0.17)$ & $(0.14)$ \\
\hline \multirow[t]{2}{*}{$\mathrm{D}$} & 622 & 360 & 262 & 0.39 & 1.26 \\
\hline & & & & $(0.17)$ & $(0.78)$ \\
\hline \multirow[t]{2}{*}{$\mathrm{E}$} & 1,264 & 886 & 378 & 0.26 & 1.18 \\
\hline & & & & $(0.13)$ & $(0.17)$ \\
\hline \multirow[t]{2}{*}{$\mathrm{F}$} & 654 & 452 & 202 & 0.70 & 1.11 \\
\hline & & & & $(0.22)$ & $(0.14)$ \\
\hline \multirow[t]{2}{*}{$\mathrm{G}$} & 686 & 414 & 272 & 0.62 & 1.15 \\
\hline & & & & $(0.17)$ & $(0.18)$ \\
\hline \multirow[t]{2}{*}{ Total } & 4,487 & 3,039 & 1,448 & 0.41 & 1.17 \\
\hline & & & & $(0.24)$ & $(0.32)$ \\
\hline
\end{tabular}

\begin{tabular}{lrrrrr}
\hline $\begin{array}{l}\text { Panel B: index as underlying } \\
\text { Investment Bank }\end{array}$ & & & \multicolumn{3}{c}{ At Issuance } \\
& \#Products & \#Calls & \#Puts & Maturity & Moneyness \\
\hline A & 89 & 51 & 38 & 0.15 & 1.05 \\
& & & & $(0.12)$ & $(0.05)$ \\
B & 522 & 281 & 241 & 0.24 & 1.05 \\
& & & & $(0.18)$ & $(0.05)$ \\
C & 346 & 158 & 188 & 0.20 & 1.06 \\
& & & & $(0.14)$ & $(0.07)$ \\
D & 43 & 15 & 28 & 0.62 & 1.11 \\
& & & & $(0.24)$ & $(0.07)$ \\
E & 291 & 155 & 136 & 0.15 & 1.06 \\
& & & & $(0.07)$ & $(0.07)$ \\
F & 256 & 120 & 136 & 0.26 & 1.05 \\
& & & & $(0.10)$ & $(0.06)$ \\
G & 36 & 11 & 25 & 0.21 & 1.05 \\
& & & & $(0.10)$ & $(0.03)$ \\
\hline Total & 1,583 & 791 & 792 & 0.22 & 1.06 \\
& & & & $(0.16)$ & $(0.06)$ \\
\hline
\end{tabular}


Table 3

Descriptive Statistics - News

Our sample includes 12,556 news messages provided by Thomson Reuters NewsScope Real-time for all DAX30 constitutents. News are tagged with data from Thomson Reuters NewsScope Sentiment Engine (RNSE) which enriches news data with sentiment, affected RIC, and relevance. Sentiment is either positive (+), neutral (0) or negative (-). Standard deviations are reported in brackets.

\begin{tabular}{|c|c|c|c|c|c|}
\hline \multicolumn{2}{|r|}{ Company } & \multicolumn{4}{|c|}{ News Messages } \\
\hline RIC & Name & \#Total & $\#+$ & $\# 0$ & $\#-$ \\
\hline ADSG.DE & adidas AG & 181 & 75 & 27 & 79 \\
\hline ALVG.DE & Allianz SE & 421 & 173 & 70 & 178 \\
\hline BASF.DE & BASF AG & 299 & 124 & 52 & 123 \\
\hline BAYG.DE & Bayer AG & 230 & 80 & 39 & 111 \\
\hline BEIG.DE & Beiersdorf AG & 117 & 50 & 18 & 49 \\
\hline BMWG.DE & Bayerische Motoren Werke AG & 407 & 172 & 79 & 156 \\
\hline CBKG.DE & Commerzbank & 478 & 149 & 91 & 238 \\
\hline DAIGn.DE & Daimler AG & 697 & 269 & 126 & 302 \\
\hline DB1Gn.DE & Deutsche Brse AG & 923 & 114 & 59 & 750 \\
\hline DBKGn.DE & Deutsche Bank AG & 1,720 & 578 & 362 & 780 \\
\hline DPWGn.DE & Deutsche Post AG & 234 & 83 & 30 & 121 \\
\hline DTEGn.DE & Deutsche Telekom AG & 612 & 233 & 92 & 287 \\
\hline EONGn.DE & E.ON SE & 675 & 279 & 151 & 245 \\
\hline FMEG.DE & Fresenius Medical Care AG \& Co KGaA & 61 & 36 & 13 & 12 \\
\hline FREG_p.DE & Fresenius SE \& Co KGaA & 54 & 31 & 11 & 12 \\
\hline HNKG_p.DE & Henkel AG \& Co. KGaA & 137 & 74 & 19 & 44 \\
\hline HNRGn.DE & Hannover Rueckversicherung AG & 108 & 50 & 11 & 47 \\
\hline IFXGn.DE & Infineon Technologies AG & 273 & 143 & 39 & 91 \\
\hline LHAG.DE & Lufhansa AG & 548 & 160 & 77 & 311 \\
\hline LING.DE & Linde AG & 101 & 57 & 10 & 34 \\
\hline MANG.DE & MAN SE & 221 & 90 & 37 & 94 \\
\hline MEOG.DE & Metro AG & 241 & 95 & 45 & 101 \\
\hline MRCG.DE & Merck KGaA & 220 & 74 & 35 & 111 \\
\hline MUVGn.DE & $\begin{array}{l}\text { Muenchner Rueckversicherungs- } \\
\text { Gesellschaft AG }\end{array}$ & 203 & 81 & 28 & 94 \\
\hline RWEG.DE & RWE AG & 616 & 282 & 142 & 192 \\
\hline SAPG.DE & SAP AG & 341 & 152 & 58 & 131 \\
\hline SDFG.DE & $\mathrm{K}+\mathrm{S} \mathrm{AG}$ & 209 & 81 & 20 & 108 \\
\hline SIEGn.DE & Siemens AG & 744 & 337 & 137 & 270 \\
\hline SZGG.DE & Salzgitter AG & 111 & 44 & 17 & 50 \\
\hline TKAG.DE & ThyssenKrupp AG & 286 & 114 & 43 & 129 \\
\hline VOWG.DE & Volswagen AG & 1,088 & 417 & 257 & 414 \\
\hline Total & & 12,556 & 4,697 & 2,195 & 5,664 \\
\hline Mean & & $\begin{array}{r}405 \\
(352.18)\end{array}$ & $\begin{array}{r}152 \\
(121.64)\end{array}$ & $\begin{array}{r}71 \\
(75.45)\end{array}$ & $\begin{array}{r}183 \\
(180.76)\end{array}$ \\
\hline Median & & 273 & 114 & 43 & 121 \\
\hline
\end{tabular}




\section{Table 4}

\section{Profitability}

This table captures the mean percentage performance (Raw Return) and sharpe ratio (Adj. Return) across all observations assuming a buy-and-hold strategy for different horizons: 30 minutes, one to four trading hours, and one, two, and five trading days. Periods exceeding trading hours of a day are continued at trading hours on the following day. Results are differentiated by the type of underlying: index or stock. T-values are reported in brackets. */**/*** denotes significance below the 5\%/1\%, and $0.1 \%$ level, respectively.

\begin{tabular}{lcccc}
\hline & \multicolumn{2}{c}{ Stock as Underlying } & \multicolumn{2}{c}{ Index as Underlying } \\
& Raw Return [\%] & Adj. Return [\%] & Raw Return [\%] & Adj. Return [\%] \\
\hline Buy-and-Hold & & & & \\
$0.5 \mathrm{~h}$ & $-4.96^{* * *}$ & $-4.13^{* * *}$ & $-1.79^{* * *}$ & $-0.69^{* * *}$ \\
& $(-51.38)$ & $(-33.82)$ & $(-39.30)$ & $(-32.35)$ \\
1h & $-5.22^{* * *}$ & $-2.99^{* * *}$ & $-1.40^{* *}$ & $-0.53^{* * *}$ \\
& $(-45.32)$ & $(-32.98)$ & $(-22.69)$ & $(-35.88)$ \\
2h & $-5.21^{* * *}$ & $-2.21^{* * *}$ & $-0.77^{* * *}$ & $-0.38^{* * *}$ \\
& $(-38.55)$ & $(-27.65)$ & $(-9.87)$ & $(-22.74)$ \\
$3 \mathrm{~h}$ & $-5.54^{* * *}$ & $-1.89^{* * *}$ & $-0.37^{* * *}$ & $-0.26^{* * *}$ \\
& $(-34.75)$ & $(-26.05)$ & $(-4.03)$ & $(-18.38)$ \\
$4 \mathrm{~h}$ & $-6.06^{* * *}$ & $-1.77^{* * *}$ & -0.03 & $-0.21^{* * *}$ \\
& $(-34.34)$ & $(-27.80)$ & $(-0.31)$ & $(-15.66)$ \\
1d & $-7.74^{* * *}$ & $-0.97^{* * *}$ & $1.79^{* * *}$ & 0.01 \\
& $(-29.56)$ & $(-25.95)$ & $(11.52)$ & $(0.68)$ \\
2d & $-9.45^{* * *}$ & $-1.01^{* * *}$ & $2.56^{* * *}$ & 0.01 \\
& $(-29.47)$ & $(-26.29)$ & $(12.97)$ & $(1.00)$ \\
5d & $-6.48^{* * *}$ & $-0.56^{* * *}$ & $7.82^{* * *}$ & $0.24^{* * *}$ \\
& $(-15.82)$ & $(-16.29)$ & $(27.56)$ & $(21.94)$ \\
\hline
\end{tabular}


Table 5

Profitability of Leveraged Trades

This table captures the mean and median percentage performance (Raw Return) across all observations assuming a buy-and-hold strategy for different horizons: 30 minutes, one to four trading hours, and one, two, and five trading days. We cluster investor trades by terciles of traded leverage ratios. Periods exceeding trading hours of a day are continued at trading hours on the following day. Results are differentiated by the type of underlying: stock (panel A) or index (panel B). T-values are reported in brackets. $* / * * / * * *$ denotes significance below the $5 \% / 1 \%$, and $0.1 \%$ level, respectively.

\begin{tabular}{|c|c|c|c|c|c|c|}
\hline \multicolumn{7}{|c|}{ Panel A: stock as underlying } \\
\hline & \multirow{2}{*}{\multicolumn{2}{|c|}{$\begin{array}{c}\text { High } \\
\text { Raw Return [\%] }\end{array}$}} & \multirow{2}{*}{\multicolumn{2}{|c|}{$\begin{array}{c}\text { Medium } \\
\text { Raw Return [\%] }\end{array}$}} & \multirow{2}{*}{\multicolumn{2}{|c|}{$\begin{array}{c}\text { Low } \\
\text { Raw Return [\%] }\end{array}$}} \\
\hline & & & & & & \\
\hline & Mean & Median & Mean & Median & Mean & Median \\
\hline \multicolumn{7}{|c|}{ Buy-and-Hold } \\
\hline $0.5 \mathrm{~h}$ & $\begin{array}{c}-6.44^{* * *} \\
-(27.99)\end{array}$ & -4.32 & $\begin{array}{l}-4.47^{* * *} \\
-(33.75)\end{array}$ & -3.29 & $\begin{array}{c}-3.93^{\text {*** }} \\
-(36.83)\end{array}$ & -2.71 \\
\hline $1 \mathrm{~h}$ & $\begin{array}{c}-6.75^{* * *} \\
-(24.85)\end{array}$ & -4.46 & $\begin{array}{c}-4.67^{* * *} \\
-(28.72)\end{array}$ & -3.28 & $\begin{array}{c}-4.19^{* * *} \\
-(32.26)\end{array}$ & -2.83 \\
\hline $2 \mathrm{~h}$ & $\begin{array}{c}-6.92^{* * *} \\
-(21.25)\end{array}$ & -4.31 & $\begin{array}{c}-4.54^{* * *} \\
-(24.71)\end{array}$ & -3.36 & $\begin{array}{c}-4.15^{\text {*** }} \\
-(27.76)\end{array}$ & -2.86 \\
\hline $3 \mathrm{~h}$ & $\begin{array}{c}-7.13^{\text {*** }} \\
-(18.22)\end{array}$ & -4.23 & $\begin{array}{c}-4.97^{* * *} \\
-(23.51)\end{array}$ & -3.25 & $\begin{array}{c}-4.50^{* * *} \\
-(26.93)\end{array}$ & -2.86 \\
\hline $4 \mathrm{~h}$ & $\begin{array}{c}-7.69^{* * *} \\
-(18.37)\end{array}$ & -4.23 & $\begin{array}{c}-5.47^{* * *} \\
-(22.13)\end{array}$ & -3.57 & $\begin{array}{c}-4.98^{* * *} \\
-(24.91)\end{array}$ & -2.93 \\
\hline $1 d$ & $\begin{array}{l}-10.03^{* * *} \\
-(16.02)\end{array}$ & -5.99 & $\begin{array}{c}-7.89^{* * *} \\
-(19.89)\end{array}$ & -4.31 & $\begin{array}{c}-6.29^{* * *} \\
-(22.12)\end{array}$ & -3.12 \\
\hline $2 \mathrm{~d}$ & $\begin{array}{l}-11.63^{\text {*** }} \\
-(15.20)\end{array}$ & -7.10 & $\begin{array}{c}-9.49^{* * *} \\
-(19.73)\end{array}$ & -5.20 & $\begin{array}{c}-7.66^{* * *} \\
-(22.10)\end{array}$ & -3.38 \\
\hline $5 \mathrm{~d}$ & $\begin{array}{l}-6.99^{* * *} \\
-(7.03)\end{array}$ & -7.24 & $\begin{array}{l}-5.40^{* * *} \\
-(8.56)\end{array}$ & -4.07 & $\begin{array}{c}-7.64^{* * *} \\
-(17.82)\end{array}$ & -2.79 \\
\hline
\end{tabular}

continued on the next page... 
Table 5

Table 5-continued

\begin{tabular}{|c|c|c|c|c|c|c|}
\hline \multicolumn{7}{|c|}{ Panel B: index as underlying } \\
\hline & \multirow{2}{*}{\multicolumn{2}{|c|}{$\begin{array}{c}\text { High } \\
\text { Raw Return [\%] }\end{array}$}} & \multirow{2}{*}{\multicolumn{2}{|c|}{$\begin{array}{c}\text { Medium } \\
\text { Raw Return [\%] }\end{array}$}} & \multirow{2}{*}{\multicolumn{2}{|c|}{$\begin{array}{c}\text { Low } \\
\text { Raw Return [\%] }\end{array}$}} \\
\hline & & & & & & \\
\hline & Mean & Median & Mean & Median & Mean & Median \\
\hline \multicolumn{7}{|c|}{ Buy-and-Hold } \\
\hline \multirow[t]{2}{*}{$0.5 \mathrm{~h}$} & $-2.35^{* * *}$ & -1.60 & $-1.77 * * *$ & -1.40 & $-1.26^{* * *}$ & -0.88 \\
\hline & $-(19.52)$ & & $-(33.50)$ & & $-(36.01)$ & \\
\hline \multirow[t]{2}{*}{$1 \mathrm{~h}$} & $-0.48^{* *}$ & -0.65 & $-1.86^{* * *}$ & -1.45 & $-1.35^{* * *}$ & -0.89 \\
\hline & $-(2.85)$ & & $-(25.41)$ & & $-(28.17)$ & \\
\hline \multirow[t]{2}{*}{$2 \mathrm{~h}$} & $1.66^{* * *}$ & 0.40 & $-1.70^{* * *}$ & -1.58 & $-1.57^{* * *}$ & -1.10 \\
\hline & $(7.71)$ & & $-(17.93)$ & & $-(27.58)$ & \\
\hline \multirow[t]{2}{*}{$3 \mathrm{~h}$} & $3.55^{* * *}$ & 1.37 & $-1.92^{* * *}$ & -1.86 & $-1.72^{* * *}$ & -1.15 \\
\hline & $(14.09)$ & & $-(16.95)$ & & $-(25.78)$ & \\
\hline \multirow[t]{2}{*}{$4 \mathrm{~h}$} & $5.17^{* * *}$ & 2.50 & $-2.10^{* * *}$ & -2.02 & $-1.98^{* * *}$ & -1.38 \\
\hline & $(18.00)$ & & $-(16.05)$ & & $-(25.92)$ & \\
\hline \multirow[t]{2}{*}{$1 d$} & $11.48^{* * *}$ & 7.22 & $-0.55^{* *}$ & -1.52 & $-2.16^{* * *}$ & -1.52 \\
\hline & $(26.08)$ & & $-(2.61)$ & & $-(18.65)$ & \\
\hline \multirow[t]{2}{*}{$2 \mathrm{~d}$} & $15.33^{* * *}$ & -2.80 & $1.13^{* * *}$ & -1.74 & $-2.71^{* * *}$ & -2.33 \\
\hline & $(25.92)$ & & $(3.73)$ & & $-(16.34)$ & \\
\hline \multirow[t]{2}{*}{$5 \mathrm{~d}$} & $21.68^{* * *}$ & -99.89 & $4.50 * * *$ & -0.16 & $-4.39 * * *$ & -3.15 \\
\hline & $(27.47)$ & & $(9.91)$ & & $-(17.02)$ & \\
\hline
\end{tabular}




\section{Table 6}

Volume, Leverage and Order Type

This table reports results for the truncated regression model measuring the influence of volume, leverage and order type on the raw relative return of retail investors. We define an order as marketable if it is executed within one second after submission. All other orders are labeled limit orders. Let Volume $_{j}$ denote the number of shares bought times buy price, and Leverage $i_{i t_{0}(j)}$ be the leverage ratio of buy order $j$.

$$
\text { Ret }_{i j h}=\alpha+\beta_{1} \times \text { Leverage }_{i t_{0}(j)}+\beta_{2} \times \text { Volume }_{i j}+\beta_{3} \times D_{i j}^{\text {Limit }}+\beta_{4} \times D_{i j}^{\text {Call }}+\epsilon_{j} .
$$

where $D_{i j}^{L i m i t}$ denotes a dummy variable set to one if the order is a limit order and zero otherwise; $D_{i j}^{C a l l}$ is a dummy variable indicating a call $(=1)$ or put $(=0)$ product.Leverage and Volume variables are standardized. Performance is measured assuming a buy-and-hold strategy for different horizons: 30 minutes, one to four trading hours, and one, two, and five trading days. Periods exceeding trading hours of a day are continued at trading hours on the following day. We run the regression separately for each assumed holding period. Results are differentiated by the type of underlying: panel A for products with stock as underlying, and panel B for products with index as underlying. T-values are reported in brackets. ${ }^{*} / * * / * * *$ denotes significance below the $5 \% / 1 \%$, and $0.1 \%$ level, respectively.

\begin{tabular}{lcccccccc}
\hline \multicolumn{2}{l}{ Panel A: stock as underlying } & \multicolumn{9}{c}{ Buy-and-Hold } & \multicolumn{2}{c}{} \\
& $0.5 \mathrm{~h}$ & $1 \mathrm{~h}$ & $2 \mathrm{~h}$ & $3 \mathrm{~h}$ & $4 \mathrm{~h}$ & $1 \mathrm{~d}$ & $2 \mathrm{~d}$ & $5 \mathrm{~d}$ \\
\hline Intercept & $-3.94^{* * *}$ & $-4.23^{* * *}$ & $-4.41^{* * *}$ & $-4.44^{* * *}$ & $-4.82^{* * *}$ & $-6.55^{* * *}$ & $-8.82^{* * *}$ & $-14.30^{* * *}$ \\
& $(-13.10)$ & $(-11.75)$ & $(-10.44)$ & $(-8.91)$ & $(-8.73)$ & $(-7.66)$ & $(-7.61)$ & $(-7.71)$ \\
Leverage & -0.16 & $-0.54^{* * *}$ & $-0.82^{* * *}$ & $1.13^{* * *}$ & $0.54^{* *}$ & 0.12 & $1.27^{* * *}$ & $3.00^{* * *}$ \\
& $(-1.64)$ & $(-4.68)$ & $(-5.96)$ & $(7.02)$ & $(3.05)$ & $(0.43)$ & $(3.54)$ & $(5.35)$ \\
Volume & $0.86^{* * *}$ & $0.80^{* * *}$ & $0.82^{* * *}$ & $0.98^{* * *}$ & $1.17^{* * *}$ & $1.15^{*}$ & $1.80^{* * *}$ & $2.44^{* * *}$ \\
& $(8.77)$ & $(6.95)$ & $(5.77)$ & $(6.09)$ & $(6.62)$ & $(4.17)$ & $(4.93)$ & $(4.43)$ \\
Limit Order & $-2.63^{* * *}$ & $-2.33^{* * *}$ & $-1.93^{* * *}$ & $-2.12^{* * *}$ & $-2.52^{* * *}$ & $-3.46^{* * *}$ & $-4.80^{* * *}$ & $-6.18^{* * *}$ \\
& $(-9.08)$ & $(-6.69)$ & $(-4.73)$ & $(-4.40)$ & $(-4.73)$ & $(-4.19)$ & $(-4.30)$ & $(-3.53)$ \\
Call & $1.84^{* * *}$ & $1.50^{* * *}$ & $1.28^{* * *}$ & $1.07^{* *}$ & $1.36^{* * *}$ & $1.74^{* *}$ & 0.29 & -0.50 \\
& $(8.83)$ & $(6.02)$ & $(4.36)$ & $(3.11)$ & $(3.55)$ & $(2.92)$ & $(0.36)$ & $(-0.39)$ \\
\hline
\end{tabular}

continued on the next page... 
Table 6

Table 6- continued

\begin{tabular}{|c|c|c|c|c|c|c|c|c|c|}
\hline & \multicolumn{5}{|c|}{ Panel B: index as underlying } & \multicolumn{4}{|c|}{ Buy-and-Hold } \\
\hline & & $0.5 \mathrm{~h}$ & $1 \mathrm{~h}$ & $2 \mathrm{~h}$ & $3 \mathrm{~h}$ & $4 \mathrm{~h}$ & $1 d$ & $2 \mathrm{~d}$ & $5 \mathrm{~d}$ \\
\hline & Intercept & $-1.06^{* * *}$ & $-0.63^{* *}$ & $-0.51^{*}$ & 0.17 & $-0.86^{*}$ & $-14.07^{* * *}$ & $-71.05^{* * *}$ & $-2,280.41^{* * *}$ \\
\hline \multirow{9}{*}{$\underset{\mapsto}{\infty}$} & & $(-7.34)$ & $(-3.21)$ & $(-2.06)$ & $(0.58)$ & $(-2.51)$ & $(-20.13)$ & $(-42.48)$ & $(-15.52)$ \\
\hline & Leverage & $-0.34^{* * *}$ & $0.86^{* * *}$ & $1.77^{* * *}$ & $2.86^{* * *}$ & $3.23^{* * *}$ & $2.27^{* * *}$ & $4.20^{* * *}$ & $33.25^{* * *}$ \\
\hline & & $(-6.22)$ & $(11.62)$ & $(18.63)$ & $(25.44)$ & $(24.92)$ & $(11.41)$ & $(11.93)$ & $(13.06)$ \\
\hline & Volume & 0.03 & 0.00 & -0.14 & $-0.20^{*}$ & $-0.25^{*}$ & $-0.99^{* * *}$ & $-1.84^{* * *}$ & $-34.58^{* * *}$ \\
\hline & & $(0.71)$ & $(0.02)$ & $(-1.79)$ & $(-2.16)$ & $(-2.27)$ & $(-4.12)$ & $(-3.54)$ & $(-4.00)$ \\
\hline & Limit Order & $-0.75^{* * *}$ & $-0.86^{* * *}$ & $-0.51^{*}$ & $-0.89 * *$ & -0.16 & $3.20^{* * *}$ & $10.20^{* * *}$ & $242.80^{* * *}$ \\
\hline & & $(-5.17)$ & $(-4.35)$ & $(-2.05)$ & $(-3.00)$ & $(-0.47)$ & $(4.66)$ & $(7.17)$ & $(9.97)$ \\
\hline & Call & -0.14 & 0.00 & $0.50^{* *}$ & 0.33 & $1.13^{* * *}$ & $2.40^{* * *}$ & $3.29^{* * *}$ & $224.84^{* * *}$ \\
\hline & & $(-1.46)$ & $(0.04)$ & $(3.17)$ & $(1.77)$ & $(5.18)$ & $(5.56)$ & $(3.72)$ & $(12.94)$ \\
\hline
\end{tabular}




\section{Table 7}

Retail Investor Trading Intensity Around News

This table provides results for trading intensity measures around news for retail investors. The terms Positive, Negative and Neutral refer to the sentiment analysis of the Reuters NewsScope Sentiment Engine. Before and After denote the period of six hours before and after individual news. We build intervals $I_{1}, I_{2}$, and $I_{3}$ for different periods before and after news events:

$$
I_{n t}= \begin{cases}1 & n=1: \text { if } \mathrm{t} \text { is } 6 \text { hours before a news } \\ & n=2: \text { if } \mathrm{t} \text { is } 6 \text { hours after a news } \\ 0 & \text { else. }\end{cases}
$$

We build sentiment dummy variables $S_{m t}$ separately for positive $(m=1)$, negative $(m=2)$, and neutral $(m=3)$ news. They are set to one within a range of six hours around a positive, negative, and neutral news event, respectively. Let $l$ denote an observation in our data set, and $x$ denotes the underlying. We include dummy variables for the underlying $(U)$, for the hour of the day $(T)$, and the day of the week $(W)$. Let $M_{x l}$ denote the trading intensity measure for underlying $x$ and observation $l$. Results are obtained running the following regression model using Newey-West standard errors:

$$
M_{x l}=\alpha+\sum_{n=1}^{2} \sum_{m=1}^{3} \psi_{n m} I_{n x l} S_{m x l}+\sum_{x=1}^{31} v_{x} U_{x}+\sum_{t=1}^{11} \tau_{t} T_{t}+\sum_{d=1}^{4} \omega_{d} W_{d}+\epsilon_{x} .
$$

T-values are reported in brackets. $* /^{* *} / * * *$ denotes significance below the $5 \% / 1 \%$, and $0.1 \%$ level, respectively.

\begin{tabular}{lcccccc}
\hline & \multicolumn{2}{c}{ Positive } & \multicolumn{2}{c}{ Negative } & \multicolumn{2}{c}{ Neutral } \\
& Before & After & Before & After & Before & After \\
\hline \#Trades per Min. [× 10k] & $9.79^{* * *}$ & $7.48^{* * *}$ & $12.27^{* * *}$ & $12.39^{* * *}$ & $4.76^{* *}$ & $9.68^{* * *}$ \\
& $(6.50)$ & $(5.39)$ & $(9.25)$ & $(9.64)$ & $(2.68)$ & $(5.16)$ \\
Volume per Min. & $2.49^{*}$ & 0.23 & $4.39^{* * *}$ & $4.22^{* * *}$ & -1.99 & $3.90^{*}$ \\
& $(2.24)$ & $(0.23)$ & $(3.76)$ & $(3.74)$ & $(-1.32)$ & $(2.25)$ \\
\#Long Positions per Min. [× 10k] $]$ & $4.65^{* * *}$ & $5.02^{* * *}$ & $7.30^{* * *}$ & $6.19^{* * *}$ & 0.41 & $6.99^{* * *}$ \\
& $(4.50)$ & $(4.84)$ & $(6.86)$ & $(6.19)$ & $(0.28)$ & $(4.51)$ \\
\#Short Positions per Min. [× 10k] & $5.14^{* * *}$ & $2.46^{* *}$ & $4.98^{* * *}$ & $6.20^{* * *}$ & $4.35^{* * *}$ & $2.70^{* *}$ \\
& $(4.74)$ & $(2.70)$ & $(6.40)$ & $(7.83)$ & $(4.24)$ & $(2.59)$ \\
\hline
\end{tabular}




\section{Table 8}

News Trading

We analyze for each trade the difference in time to the next news ahead. Reported values are the mean relative performance [\%] (Raw Ret.) and sharpe ratio (Adj. Ret.) [\%] across all trades differentiated by their distance in time to the news after (Prediction) the trade. Performance is measured assuming a buy-and-hold strategy for different horizons: 30 minutes, one to four trading hours, and one, two, and five trading days. Periods exceeding trading hours of a day are continued at trading hours on the following day. T-values are reported in brackets. All estimates are significant below the $0.1 \%$ level.

\begin{tabular}{|c|c|c|c|c|c|c|c|c|c|c|}
\hline \multirow[t]{2}{*}{ Prediction } & \multicolumn{2}{|c|}{$\mathrm{t}<0.5 \mathrm{~h}$} & \multicolumn{2}{|c|}{$0.5 \mathrm{~h} \leq \mathrm{t}<1 \mathrm{~h}$} & \multicolumn{2}{|c|}{$1 \mathrm{~h} \leq \mathrm{t}<5 \mathrm{~h}$} & \multicolumn{2}{|c|}{$5 \mathrm{~h} \leq \mathrm{t}<24 \mathrm{~h}$} & \multicolumn{2}{|c|}{ else } \\
\hline & Raw Ret. & Adj. Ret. & Raw Ret. & Adj. Ret. & Raw Ret. & Adj. Ret. & Raw Ret. & Adj. Ret. & Raw Ret. & Adj. Ret. \\
\hline \multicolumn{11}{|c|}{ Buy-and-Hold } \\
\hline \multirow[t]{2}{*}{$0.5 \mathrm{~h}$} & -5.39 & -4.01 & & & & & & & -4.71 & -3.88 \\
\hline & $(-17.16)$ & $(-12.66)$ & & & & & & & $(-26.97)$ & $(-19.01)$ \\
\hline \multirow[t]{2}{*}{$1 \mathrm{~h}$} & -5.58 & -3.14 & -5.95 & -2.99 & & & & & -4.83 & -2.76 \\
\hline & $(-15.16)$ & $(-11.95)$ & $(-12.24)$ & $(-9.63)$ & & & & & $(-24.56)$ & $(-16.50)$ \\
\hline \multirow[t]{2}{*}{$2 \mathrm{~h}$} & -5.85 & -2.53 & -6.19 & -2.13 & -5.06 & -2.09 & & & -5.13 & -2.22 \\
\hline & $(-13.35)$ & $(-14.04)$ & $(-11.41)$ & $(-10.61)$ & $(-18.79)$ & $(-18.11)$ & & & $(-20.87)$ & $(-10.03)$ \\
\hline \multirow[t]{2}{*}{$3 \mathrm{~h}$} & -6.65 & -2.14 & -7.04 & -1.79 & -5.86 & -1.89 & & & -4.86 & -1.53 \\
\hline & $(-13.78)$ & $(-12.63)$ & $(-11.37)$ & $(-10.84)$ & $(-18.63)$ & $(-15.64)$ & & & $(-15.46)$ & $(-14.88)$ \\
\hline \multirow[t]{2}{*}{$4 h$} & -7.52 & -1.76 & -8.28 & -2.02 & -6.77 & -1.82 & & & -5.13 & -1.44 \\
\hline & $(-14.41)$ & $(-15.04)$ & $(-11.14)$ & $(-9.78)$ & $(-18.96)$ & $(-14.44)$ & & & $(-15.38)$ & $(-12.57)$ \\
\hline \multirow[t]{2}{*}{$1 d$} & -9.25 & -1.20 & -11.22 & -1.46 & -9.09 & -1.18 & -6.01 & -0.72 & -7.10 & -0.83 \\
\hline & $(-11.78)$ & $(-12.72)$ & $(-10.44)$ & $(-9.53)$ & $(-16.47)$ & $(-14.82)$ & $(-12.22)$ & $(-11.52)$ & $(-15.53)$ & $(-10.63)$ \\
\hline \multirow[t]{2}{*}{$2 \mathrm{~d}$} & -11.49 & -1.37 & -12.31 & -1.28 & -9.90 & -1.19 & -8.82 & -0.81 & -8.28 & -0.85 \\
\hline & $(-12.44)$ & $(-11.62)$ & $(-9.87)$ & $(-9.84)$ & $(-14.49)$ & $(-13.08)$ & $(-14.93)$ & $(-12.45)$ & $(-14.13)$ & $(-12.31)$ \\
\hline \multirow[t]{2}{*}{$5 \mathrm{~d}$} & -9.31 & -0.70 & -10.73 & -0.78 & -6.93 & -0.68 & -5.70 & -0.36 & -4.89 & -0.54 \\
\hline & $(-8.34)$ & $(-7.83)$ & $(-6.89)$ & $(-6.09)$ & $(-8.03)$ & $(-9.87)$ & $(-7.67)$ & $(-5.63)$ & $(-6.27)$ & $(-7.94)$ \\
\hline
\end{tabular}




\section{Table 9}

Implicit Costs Sensitivity

We distinguish trades by the ratio of leverage to implicit costs. Implicit costs consists of the hidden incorporated product premium $(P)$ and the bid-ask spread (Spread). Figure 4 visualizes this ratio with respect to moneyness. We define a trade as sensitive if the net leverage of a product $i$ at time $t$

$$
\text { leverage }_{i t}^{\text {Net }}=\frac{\text { leverage }_{i t}}{P_{i t}+\text { Spread }_{i t}},
$$

is higher than 2.5, and otherwise as non-sensitive. Reported results are the mean relative return [\%] (Raw Return) and sharpe ratio (Adj. Return) [\%] across all trades belonging to those groups. Differences are calculated by substracting the mean sensitive return for each holding period from individual non-sensitive trade returns. T-values are reported in brackets. $* / * * / * * *$ denotes significance below the $5 \% / 1 \%$, and $0.1 \%$ level, respectively.

\begin{tabular}{|c|c|c|c|c|c|c|}
\hline & \multicolumn{2}{|c|}{ Non-sensitive Investors } & \multicolumn{2}{|c|}{ Sensitive Investors } & \multicolumn{2}{|c|}{ Difference: Non-Sensitive - Sensitive } \\
\hline & Raw Return [\%] & Adj. Return [\%] & Raw Return [\%] & Adj. Return [\%] & Raw Return [\%] & Adj. Return [\%] \\
\hline \multicolumn{7}{|c|}{ Buy-and-Hold } \\
\hline \multirow[t]{2}{*}{$0.5 \mathrm{~h}$} & -2.07 & -1.27 & 1.29 & 0.08 & $-3.36^{* * *}$ & $-1.36^{* * *}$ \\
\hline & $(-42.21)$ & $(-37.86)$ & $(21.61)$ & $(2.95)$ & $(-68.57)$ & $(-40.30)$ \\
\hline \multirow[t]{2}{*}{$1 \mathrm{~h}$} & -2.65 & -1.19 & 4.17 & 0.62 & $-6.82^{* * *}$ & $-1.80^{* * *}$ \\
\hline & $(-42.98)$ & $(-39.51)$ & $(48.33)$ & $(22.92)$ & $(-110.48)$ & $(-59.95)$ \\
\hline \multirow[t]{2}{*}{$2 \mathrm{~h}$} & -2.93 & -1.14 & 7.59 & 1.09 & $-10.51^{* * *}$ & $-2.23^{* * *}$ \\
\hline & $(-37.50)$ & $(-39.52)$ & $(60.08)$ & $(37.10)$ & $(-134.71)$ & $(-77.53)$ \\
\hline \multirow[t]{2}{*}{$3 \mathrm{~h}$} & -3.28 & -0.93 & 7.80 & 0.98 & $-11.08^{* * *}$ & $-1.91^{* * *}$ \\
\hline & $(-32.61)$ & $(-32.22)$ & $(52.93)$ & $(33.56)$ & $(-110.04)$ & $(-65.94)$ \\
\hline \multirow[t]{2}{*}{$4 \mathrm{~h}$} & -3.24 & -0.72 & 7.77 & 0.77 & $-11.00^{* * *}$ & $-1.49^{* * *}$ \\
\hline & $(-27.38)$ & $(-29.77)$ & $(47.98)$ & $(31.64)$ & $(-93.10)$ & $(-61.69)$ \\
\hline \multirow[t]{2}{*}{$1 d$} & -3.50 & -0.39 & 10.07 & 0.48 & $-13.57^{* * *}$ & $-0.87^{* * *}$ \\
\hline & $(-18.37)$ & $(-22.93)$ & $(42.02)$ & $(28.13)$ & $(-71.11)$ & $(-51.09)$ \\
\hline \multirow[t]{2}{*}{$2 \mathrm{~d}$} & -3.56 & -0.36 & 12.39 & 0.45 & $-15.95 * * *$ & $-0.81^{* * *}$ \\
\hline & $(-14.08)$ & $(-19.76)$ & $(39.07)$ & $(26.15)$ & $(-63.14)$ & $(-44.15)$ \\
\hline \multirow[t]{2}{*}{$5 \mathrm{~d}$} & -1.14 & -0.05 & 17.78 & 0.58 & $-18.92^{* * *}$ & $-0.64^{* * *}$ \\
\hline & $(-2.93)$ & $(-2.35)$ & $(38.82)$ & $(27.72)$ & $(-48.77)$ & $(-29.68)$ \\
\hline
\end{tabular}




\section{Table 10}

Implicit Costs Sensitivity - Terciles

We distinguish trades by the ratio of leverage to implicit costs. Implicit costs consists of the hidden incorporated product premium $(P)$ and the bid-ask spread. Figure 4 visualizes this ratio with respect to moneyness. We cluster trades in terciles based on the net leverage of a product $i$ at time $t$ :

$$
\text { leverage }_{i t}^{\text {Net }}=\frac{\text { leverage }_{i t}}{P_{i t}+\text { Spread }_{i t}} .
$$

Reported results are the mean relative return [\%] (Raw Return) and sharpe ratio (Adj. Return) [\%] across all trades belonging to those groups. T-values are reported in brackets. $* / * * / * * *$ denotes significance below the $5 \% / 1 \%$, and $0.1 \%$ level, respectively.

\begin{tabular}{|c|c|c|c|c|c|c|}
\hline & \multicolumn{2}{|c|}{$\begin{array}{c}\text { Sensitive } \\
\text { High }\end{array}$} & \multicolumn{2}{|c|}{ Medium } & \multicolumn{2}{|c|}{$\begin{array}{c}\text { Non-Sensitive } \\
\text { Low }\end{array}$} \\
\hline & Raw Return [\%] & Adj. Return [\%] & Raw Return [\%] & Adj. Return [\%] & Raw Return [\%] & Adj. Return [\%] \\
\hline \multicolumn{7}{|c|}{ Buy-and-Hold } \\
\hline \multirow[t]{2}{*}{$0.5 \mathrm{~h}$} & $2.13^{* * *}$ & $0.36^{* * *}$ & $-0.61 * * *$ & $-0.59 * * *$ & $-2.44^{* * *}$ & $-1.45^{* * *}$ \\
\hline & $(25.94)$ & $(9.66)$ & $(-10.46)$ & $(-18.76)$ & $(-41.98)$ & $(-34.00)$ \\
\hline \multirow[t]{2}{*}{$1 \mathrm{~h}$} & $5.96^{* * *}$ & $0.99^{* * *}$ & $0.20^{* * *}$ & $-0.30 * * *$ & $-3.39 * * *$ & $-1.42^{* * *}$ \\
\hline & $(49.14)$ & $(28.07)$ & $(2.68)$ & $(-9.63)$ & $(-46.78)$ & $(-38.32)$ \\
\hline \multirow[t]{2}{*}{$2 \mathrm{~h}$} & $10.23^{* * *}$ & $1.54^{* * *}$ & $1.99^{* * *}$ & $0.07^{*}$ & $-4.46^{* * *}$ & $-1.51^{* * *}$ \\
\hline & $(57.59)$ & $(39.94)$ & $(18.71)$ & $(2.09)$ & $(-50.98)$ & $(-42.69)$ \\
\hline \multirow[t]{2}{*}{$3 \mathrm{~h}$} & $10.50^{* * *}$ & $1.38^{* * *}$ & $2.00^{* * *}$ & 0.04 & $-4.91^{* * *}$ & $-1.21^{* * *}$ \\
\hline & $(50.96)$ & $(36.32)$ & $(15.32)$ & $(1.14)$ & $(-42.44)$ & $(-34.41)$ \\
\hline \multirow[t]{2}{*}{$4 \mathrm{~h}$} & $10.38^{* * *}$ & $1.09^{* * *}$ & $2.06^{* * *}$ & 0.05 & $-4.87 * * *$ & $-0.94^{* * *}$ \\
\hline & $(46.32)$ & $(34.61)$ & $(13.19)$ & $(1.73)$ & $(-35.93)$ & $(-32.83)$ \\
\hline \multirow[t]{2}{*}{$1 \mathrm{~d}$} & $13.98^{* * *}$ & $0.68^{* * *}$ & $2.71^{* * *}$ & $0.08^{* * *}$ & $-4.72^{* * *}$ & $-0.50 * * *$ \\
\hline & $(40.24)$ & $(28.83)$ & $(10.01)$ & $(3.80)$ & $(-20.70)$ & $(-22.75)$ \\
\hline \multirow[t]{2}{*}{$2 \mathrm{~d}$} & $17.95^{* * *}$ & $0.60^{* * *}$ & $5.10^{* * *}$ & $0.08^{* * *}$ & $-5.72^{* * *}$ & $-0.50 * * *$ \\
\hline & $(36.50)$ & $(24.38)$ & $(12.78)$ & $(3.57)$ & $(-17.37)$ & $(-20.38)$ \\
\hline \multirow[t]{2}{*}{$5 \mathrm{~d}$} & $22.11^{* * *}$ & $0.66^{* * *}$ & $10.66^{* * *}$ & $0.46^{* * *}$ & $-6.79^{* * *}$ & $-0.24^{* * *}$ \\
\hline & $(32.07)$ & $(21.65)$ & $(17.71)$ & (15.67) & $(-12.95)$ & $(-8.19)$ \\
\hline
\end{tabular}




\section{References}

Anand, A., S. Chakravarty, and T. Martell (2005): "Empirical evidence on the evolution of liquidity: Choice of market versus limit orders by informed and uninformed traders," Journal of Financial Markets, 8(3), 288-308.

Anderson, A. (2008): "Is Online Trading Gambling with Peanuts ?," Discussion paper, Swedish Institute for Financial Research.

Barber, B. M., Y.-T. Lee, Y.-J. Liu, And T. Odean (2009): "Just How Much Do Individual Investors Lose by Trading?," The Review of Financial Studies, 22(2), 609-632.

Barber, B. M., and T. Odean (2000): "Trading is Hazardous to Your Wealth: The Common Stock Investment Performance of Individual Investors," Journal of Finance, $55(2), 773-806$.

(2008): "All that Glitters: The Effect of Attention and News on the Buying Behavior of Individual and Institutional Investors," Review of Financial Studies, 21(2), $785-818$.

Bauer, R., M. Cosemans, and P. Eichholtz (2009): "Option trading and individual investor performance," Journal of Banking 6 Finance, 33(4), 731-746.

Baule, R. (2011): "The Order Flow of Discount Certificates and Issuer Pricing Behavior," Journal of Banking \& Finance, 35(11), 3120-3133.

Baule, R., O. Entrop, And M. Wilkens (2008): "Credit risk and bank margins in structured financial products: Evidence from the German secondary market for discount certificates," Journal of Futures Markets, 28(4), 376-397.

Berry, T. D., And K. M. Howe (1994): "Public information arrival," The Journal of Finance, 49(4), 1331-1346.

Black, F. (1985): "Noise," The Journal of Finance, 41(3), 529-543.

Brunnermeier, M. K., And J. A. Parker (2007): "Optimal Beliefs, Asset Prices, and the Preference for Skewed Returns," American Economic Review, 97(2), 159-165.

Doran, J. S., D. Jiang, and D. R. Peterson (2011): "Gambling Preference and the New Year Effect of Assets with Lottery Features," Review of Finance, 16(3), 685-731.

Dorn, A. J., D. Dorn, And P. F. Sengmueller (2012): "Trading as Gambling," .

Dorn, D., And P. Sengmueller (2009): "Trading as Entertainment?," Management Science, 55(4), 591-603.

Entrop, O., A. Schober, and M. Wilkens (2011): "The Pricing Policy of Banks on the German Secondary Market for Leverage Certificates: Interday and Intraday Effects," . 
GaOA, X., And T.-C. Linb (2012): "Do Individual Investors Trade Stocks as Gambling ? Evidence from Repeated Natural Experiments," .

Garrett, T. A., And R. S. Sobel (1999): "Gamblers favor skewness, not risk : Further evidence from United States lottery games," 63(1), 85-90.

Grinblatt, M., and M. Keloharju (2009): "Sensation Seeking , Overconfidence , and Trading Activity," The Journal of Finance, LXIV(2).

Han, B., And A. Kumar (2012): "Speculative Retail Trading and Asset Prices," Journal of Financial and Quantitative Analysis (JFQA), Forthcoming.

Harris, L. (2001): "Optimal Dynamic Order Submission Strategies in Some Stylized Trading Problems," Financial Markets, Institutions $\&$ Instruments, 7(2), 1-76.

Hull, J. C. (2005): Options, Futures and Other Derivatives. Prentice Hall, 6th edn.

Kelley, E. K., and P. C. Tetlock (2012): "How Wise Are Crowds ? Insights from Retail Orders and Stock Returns," The Journal of Finance, (forthcoming).

Kumar, A. (2009): "Who Gambles in the Stock Market?," The Journal of Finance, $\operatorname{LXIV}(4)$.

Lakonishok, J., I. Lee, N. D. Pearson, and A. M. Poteshman (2007): "Option Market Activity," Review of Financial Studies, 20(3), 813-857.

Newey, W. K., and K. D. West (1987): "A Simple, Positive Semi-Definite, Heteroskedasticity and Autocorelation Consistent Covariance Matrix," Econometrica, 55(3), 703-708.

Odean, T. (1999): "Do Investors Trade Too Much?," The American Economic Review, 89(5), 1279-1298.

Page, J. K., O. G. Spalt, and A. Kumar (2012): "Gambling and Comovement," .

Riordan, R., A. Storkenmaier, M. Wagener, and S. Zhang (2012): "Public information arrival: Price discovery and liquidity in electronic limit order markets," Journal of Banking \& Finance.

Rubinstein, M., and E. Reiner (1991): "Breaking down the barriers," Risk, 4, 28-35.

Schmitz, P., And M. WeBer (2012): "Buying and Selling Behavior of Individual Investors in Option-like Securities," Die Betriebswirtschaft, (5).

Stoimenov, P., And S. Wilkens (2005): "Are structured products fairly priced? An analysis of the German market for equity-linked instruments," Journal of Banking \& Finance, 29(12), 2971-2993.

Storkenmaier, A. (2011): Financial Markets and Public Information. KIT Scientific Publishing. 
Appendix 


\section{A Option Pricing Methodology}

The long (short) leverage certificate can be duplicated using the Practitioners BlackScholes model (PBS) (Black (1985)) through a down-and-out call (up-and-out put) option (Rubinstein and Reiner (1991)). We use the notation as presented in Hull (2005). The difference between the PBS model and the standard Black-Scholes model is that PBS incorporates volatility as a function of time to maturity and strike. We adjust the implied volatility parameter for each observation of each product independently.

Let $H$ be the barrier level of a barrier option, $K$ be the strike price, $S_{t}$ be the underlying price at time $t, q$ be the continuous dividend yield, $\sigma$ be the volatility of the underlying asset, and let $r$ be the risk-free rate. $N(\cdot)$ denotes the cumulative normal distribution function. $C^{E}$ and $P^{E}$ denote the price of regular call and put option, respectively. Let $C^{D I}\left(C^{D O}\right)$ be the price of a down-and-in (-out) call option, and $P^{U I}\left(P^{U O}\right)$ the price of a up-and-in (-out) put option:

long

$$
\begin{aligned}
C_{t}^{E} & =S_{t} e^{-q T} N\left(d_{1}\right)-K e^{-r T} N\left(d_{2}\right) \\
C_{t}^{D I} & =S_{t} e^{-q T}\left(H / S_{t}\right)^{2 \lambda} N(y)-K e^{-r T}\left(H / S_{t}\right)^{2 \lambda-2} N(y-\sigma \sqrt{T}) \\
C_{t}^{D O} & =C_{t}^{E}-C_{t}^{D I}
\end{aligned}
$$

short

$$
\begin{aligned}
P_{t}^{E} & =K e^{-r T} N\left(-d_{2}\right)-S_{t} e^{-q T} N\left(-d_{1}\right) \\
P_{t}^{U I} & =-S_{t} e^{-q T}\left(H / S_{t}\right)^{2 \lambda} N(-y)+K e^{-r T}\left(H / S_{t}\right)^{2 \lambda-2} N(-y+\sigma \sqrt{T}) \\
P_{t}^{U O} & =P_{t}^{E}-P_{t}^{U I}
\end{aligned}
$$


where

$$
\begin{aligned}
d_{1} & =\frac{\ln \left(S_{t} / K\right)+\left(r-q+\sigma^{2} / 2\right) T}{\sigma \sqrt{T}} \\
d_{2} & =d_{1}-\sigma \sqrt{T} \\
\lambda & =\frac{r-q+\sigma^{2} / 2}{\sigma^{2}} \\
y & =\frac{\ln \left(H^{2} /\left(S_{t} K\right)\right)}{\sigma \sqrt{T}}+\lambda \sigma \sqrt{T}
\end{aligned}
$$

To estimate the volatility parameter of the underlying, we extract the implied volatility from options traded at EUREX based on time to maturity and strike. We obtain all call and put options traded at EUREX within the sample period on a 1 min basis from SIRCA and calculate the individual implied volatility. For those leverage certificates where we do not have a perfect fit with respect to maturity and strike we interpolate quadratically in the two dimensional space spanned by implied volatility and strike price for each of two option chains having the closest maturity dates, from above and below respectively, relative to the maturity date of the leverage certificate. Finally, we obtain volatility estimates for the particular certificate by linear interpolation in time. For the risk free interest rate we are using a linear interpolated yield curve of EURIBOR rates for periods of 1 to 3 weeks and 1 to 12 months. 